\title{
On-design pre-optimization and off-design analysis of hybrid Brayton thermosolar tower power plants for different fluids and plant configurations
}

\author{
R.P. Merchan, M.J. Santos, I. Heras, J. Gonzalez-Ayala, A. Medina *, A. Calvo Hernandez \\ Department of Applied Physics and Institute of Fundamental Physics and Mathematics (IUFFYM), University of Salamanca, 37008, Salamanca, Spain
}

\section{A R T I C L E I N F O}

\section{Keywords:}

Thermosolar hybrid plants

Multi-stage brayton

On-design pre-optimization

Off-design analysis

Greenhouse emissions

\begin{abstract}
A B S T R A C T
A working fluid performs a Brayton cycle that is fed by a heat input from a solar power tower and from a combustion chamber, which burns natural gas. This hybrid system is described by a complete model that includes all the main losses and irreversibility sources (optical and thermodynamic). Numerical implementation and validation is performed based on a Spanish commercial plant. On-design computations are carried out varying the pressure ratio for four working fluids (dry air, nitrogen, carbon dioxide, and helium), for different number of stages and for recuperative and non-recuperative configurations. When adjusting the pressure ratio, an improvement of about $7 \%$ in overall thermal efficiency is predicted for a dry air single-stage recuperative configuration with respect to a standard commercial gas turbine. A study about the main energy losses in each plant subsystem for some particular plant layouts is accomplished. A two-compression and expansion stages recuperative Brayton cycle working with air is expected to give overall thermal efficiencies about 0.29 at design conditions, which is about a $47 \%$ increase with respect to the simplest single-stage configuration. It is stressing that fuel consumption from the reheaters maybe higher than that of the main combustion chamber for multistage layouts. Off-design hourly curves of output records for the four seasons throughout a day are analyzed. Greenhouse emissions are also analyzed. Specific carbon dioxide emissions are smaller for helium than for dry air, when they both work in a single-stage non-recuperative configuration.
\end{abstract}

\section{Introduction}

Climate change together with the finite reserves of fossil resources has made necessary the transformation of the energy paradigm towards new, cleaner, and renewable ways of producing energy. Concentrating Solar Power (CSP) technology constitutes one of the best ways to fulfill these requirements, taking into account its reliability and flexibility for storing or hybrid operation [1]. Particularly, the hybridization of combustion power plants is considered as a growing opportunity in the way to cleaner energy production [2]. For the production of energy at the level of a few megawatts central tower plants are expected to be, simultaneously, highly efficient and highly flexible in which respect to the technology for producing the energy through a power block [3]. The combination with other renewables as photovoltaic is also being analyzed [4]. These plants are constituted essentially by three subsystems with different physical and engineering nature: the solar field collecting the solar power and redirecting it to the tower, the solar receiver where the energy is concentrated and transferred to the working fluid, and the power subsystem, that converts energy as heat to mechanical energy through some thermodynamic cycle [5].

The solar collector in these plants is an arrange of individually nonconcentrating mirrors with a two-axis tracking system which focus light on a central receiver at the top of a tower. A common array to distribute heliostats by looking for an optimized distribution is the radial staggered [6]. The optimization process involves to calculate repeatedly the annual energy collected by the field in terms of the considered optimization variables. Most important losses should be considered, as cosine losses, shading and blocking, spillage, and atmospheric attenuation. It is also necessary to define a figure of merit, as for instance, the ratio between the cost of the field and the total thermal energy collected during a year [7]. The final aim is to reduce the levelised cost of electricity (LCOE). Different techniques have been employed during the last years, from biomimetic layouts [8], to computationally expensive Monte Carlo

\footnotetext{
* Corresponding author.

E-mail addresses: rpmerchan@usal.es (R.P. Merchan), smjesus@usal.es (M.J. Santos), iheras@usal.es (I. Heras), jgonzalezayala@usal.es (J. Gonzalez-Ayala), amd385@usal.es (A. Medina), anca@usal.es (A.C. Hernandez).
} 


\begin{tabular}{|c|c|c|c|}
\hline \multicolumn{3}{|c|}{ Nomenclature } & \multirow{2}{*}{$\begin{array}{l}\text { ambient }(W) \\
\text { lower heating value of the fuel }(\mathrm{J} / \mathrm{kg}) \\
\text { overall pressure ratio }\end{array}$} \\
\hline$A_{a}$ & aperture area of the solar field $\left(\mathrm{m}^{2}\right)$ & $r_{p}$ & \\
\hline C & solar collector concentration ratio & $R_{\min }$ & minimum radius of the heliostat field $(\mathrm{m})$ \\
\hline$C_{n}$ & nominal cleanliness & $T_{c}$ & critical temperature $(K)$ \\
\hline$c_{w}$ & specific heat of the working fluid $[\mathrm{J} / \mathrm{mol} \mathrm{K}]$ & $T_{\mathrm{HC}}$ & working temperature of the combustion chamber $(K)$ \\
\hline \multirow[t]{2}{*}{$D$} & distance between the centre of each heliostat and the aim & $T_{\mathrm{HS}}$ & working temperature of the solar collector $(K)$ \\
\hline & point in the receiver & $T_{\mathrm{L}}$ & ambient temperature $(K)$ \\
\hline$f$ & solar share & $T_{3}$ & turbines inlet temperature $(K)$ \\
\hline$f_{a t}$ & attenuation factor & THT & height of the tower supporting the receiver $(m)$ \\
\hline$f_{b}$ & blocking factor & $\bar{U}_{\mathrm{L}}$ & effective conduction-convection heat transfer coefficient \\
\hline$f_{\text {sh }}$ & shadowing factor & & {$\left[W / m^{2} K\right]$} \\
\hline$f_{s p}$ & spillage factor & $w_{r}$ & width-height ratio of the heliostat surface \\
\hline G & direct solar irradiance $\left(\mathrm{W} / \mathrm{m}^{2}\right)$ & $\alpha$ & effective emissivity \\
\hline$L R$ & height of the receiver $(m)$ & $\alpha_{S}$ & solar altitude angle $(\mathrm{rad})$ \\
\hline$M$ & molecular weight of the working fluid $(\mathrm{g} / \mathrm{mol})$ & $\Delta R$ & radial distance between two adjacent rows $(\mathrm{m})$ \\
\hline$\dot{m}$ & mass flow rate of the working substance $(\mathrm{kg} / \mathrm{s})$ & $\varepsilon_{\mathrm{HC}}$ & $\varepsilon_{\mathrm{HS}}$ combustion chamber/solar collector heat exchangers \\
\hline$\dot{m}_{f}$ & fuel mass flow rate $(\mathrm{kg} / \mathrm{s})$ & & effectiveness \\
\hline$N$ & number of compressors or turbines when they are equal & $\varepsilon_{c}$ & $\varepsilon_{t}$ isentropic efficiency of the compressors \\
\hline$N_{c} / N_{t}$ & $N_{t}$ number of compressors/turbines & $\bar{\gamma}$ & mean value of the working fluid adiabatic coefficient \\
\hline$O K$ & total number of heliostats & $\eta$ & overall thermal efficiency \\
\hline$P$ & power output $(W)$ & $\eta_{c}$ & combustion efficiency \\
\hline$p_{a m b}$ & ambient pressure (bar) & $\eta_{h}$ & thermal efficiency of the Brayton heat engine \\
\hline$p_{c}$ & critical pressure (bar) & $\bar{\eta}_{\text {hel }_{i}}$ & optical efficiency of each heliostat \\
\hline$p_{H}$ & highest pressure during heat absorption (bar) & $\eta_{s}$ & solar collector efficiency \\
\hline$p_{L}$ & pressure at the exit of the expansion processes (bar) & $\eta_{0}$ & optical efficiency of the whole field \\
\hline$\left|\dot{Q}_{\mathrm{C}}\right|$ & heat losses at the combustion chamber $(W)$ & $\rho$ & actual mirror reflectivity \\
\hline$\left|\dot{Q}_{\mathrm{H}}\right|$ & $\begin{array}{l}\text { total heat-transfer rate absorbed from the working fluid } \\
(W)\end{array}$ & $\rho_{\mathrm{H}} / \rho_{\mathrm{L}}$ & $\begin{array}{l}\rho_{\mathrm{L}} \text { irreversibilities due to pressure drops in the heat input/ } \\
\text { heat release }\end{array}$ \\
\hline$\left|\dot{Q}_{\mathrm{HC}}\right|$ & $\begin{array}{l}\text { total heat rate input from the combustion chamber and the } \\
\text { reheaters }(W)\end{array}$ & $\begin{array}{l}\rho_{n} \\
\sigma\end{array}$ & $\begin{array}{l}\text { nominal reflectivity } \\
\text { Stefan-Boltzmann constant }\left(W m^{2} K{ }^{4}\right)\end{array}$ \\
\hline$\left|\dot{Q}_{\mathrm{HS}}\right|$ & heat rate input from the solar collector $(W)$ & $\omega$ & incidence angle of the Sun radiation onto the heliostat \\
\hline$\left|\dot{Q}_{\mathrm{L}}\right|$ & heat-transfer rate between the working fluid and the & & surface $(\mathrm{rad})$ \\
\hline
\end{tabular}

ray-tracing tools (as SolTRACE [9]), and also analytical methods for simultaneously optimize heliostat field (heliostat locations and number) and the tower (tower height and receiver size) as HFLCAL, Campo Code or others [10-12].

Solar receivers are one of the crucial elements in any CSP installation, particularly central tower plants. Their design and manufacturing materials should comprise high reliability, cost-effectiveness, and a long operational lifetime [13]. Higher plant efficiencies require good light-heat conversion efficiency in the receiver [14]. This energy conversion is affected at least by four kind of losses: reflection, radiation, convection, and conduction. There are essentially two types of receiver concepts: cavity receivers and external absorption ones (for instance, a cylindrical array of tubes). The former use to have lower radiative losses than tubular, but higher convective losses [15]. Cavity receivers usually have only one aperture, so the sunlight is received only from one side, so the heliostat field should not have circular symmetry. In these receivers, outlet temperatures about $1000 C$ have been reported using air as working fluid [16]. In any case, for temperatures from 650 to $750 \mathrm{C}$ radiation effects are very important. An increase in solar absorptance and a decrease in thermal emittance are key factors to improve thermal receiver efficiency. Existing paint-based coatings, as Pyromark 2500 (currently used in central towers), with a good absorptivity are not very durable because deposition techniques nowadays only allow a limited adherence [14]. So, research lines in this field are focused to improve adhesion and maintain the optical properties above $650 \quad C$ [17].

In which respect to the thermal power block that transforms the heat released by the solar receiver in mechanical energy, most usual thermodynamic cycles are based on Rankine and Brayton cycles, i.e., steam or gas turbines, and their combination [5]. The former are usually associated to storage with molten salts in central towers, so the working fluid for the solar receiver is different to that for the power cycle itself and at least a steam generator is required. Several plants are nowadays working on this concept, not only prototype plants, but also commercial ones, as GEMASOLAR (Spain) [18], Crescent Dunes (USA) [19], and Noor III at Ouarzazate (Morocco) [20]. An interesting review on this type of plants with a summary of plants in operation and under construction is due to Behar et al. [21].

In the case of Brayton-like cycles usually the solar receiver heats air, which flows at high pressure coming from the compressor. This technology is normally linked to hybrid operation in such a way that a combustion chamber in series with the solar receiver increases, when necessary, the temperature to ensure that the turbine inlet temperature remains approximately constant. This guarantees an approximately constant power output, independently of seasonal, meteorological variations or even nighttime [22]. An increase on overall performance is obtained when a bottoming Rankine cycle is considered to take advantage of the usually high temperature of exhaust gases. The Brayton cycle can operate in both open or closed cycle schemes and a good thermal efficiency is associated to a high turbine inlet temperature. This imposes a high working temperature for the solar receiver to get also reasonably good solar shares. Usually turbine inlet temperatures are around $1100 C_{\mathrm{C}}$. These plants are still at the R\&D\&i stage. Most of prototype plant and experimental projects during the last years have been developed in Spain: SOLGATE [23], SOLHYCO [24], and SOLUGAS [25]. A major conclusion of all these projects is that the technology is feasible and interesting, but a research and development effort is still required to 
get commercially competitive prices of electricity [26].

This work is focused on the last point. Particularly, on the development of thermodynamic models for the whole plant, including all subsystems, that could allow to guide the design of future plants based on this technology. A compelling review on the thermodynamic optimization of the solar Brayton cycle was written by Le Roux et al. [27]. Osorio et al. [28] as well as McMahan et al. [29] and Zare et al. [30] have tried to model the plant in terms of a reduced set of parameters. But also detailed analysis, including thermoeconomic issues, based on simulation software have also been developed [31,32].

Thermodynamic models, as the one considered in this work, allow a comprehensive description of all plant subsystems, and so, to study the interactions among subsystems. Non-complex equations can be obtained by means of some physical parameters with a clear interpretation, so sensitivity analysis, and optimization processes can be implemented. Recently, our group presented a thermodynamic model emphasizing the details and losses in the power block [33]. In this paper a more complete model is addressed, incorporating, a detailed (but at the same time comprehensive) description of the solar subsystem. Particularly, including all the details necessary to obtain precise estimations for the optical efficiency the solar field. The model is dynamic, so it allows to predict the behavior of any plant parameter along any day of any season. And also is flexible because different working fluids can be analyzed as well as different layouts for the Brayton cycle (including single- or multi-stage compression and expansion). The model is validated for a plant of a commercial size, GEMASOLAR [18], of about $20 \mathrm{MW}$. The main sources of losses are identified and quantified for several plant configurations and daily curves of the main subsystems, and the whole plant are presented. Also the predicted temperatures of all subsystems are estimated. As a global conclusion it can be said that there is a wide inventory of options to design plants with the desired level of efficiencies or temperature limits. Once a pre-design plant scheme is adopted there is still a way to estimate the corresponding economic records, that is out of the scope of this work.

A brief description of the model developed in this work, either optical for the heliostat field or themodynamic for the power block, is presented in Sec. 2 and Appendix A. Its model implementation together with its validation are shown in Sec. 3 and Appendix B. Afterwards, Sec. 4 contains an on-design analysis of the solar plant. The performance of four different working fluids (dry air, nitrogen, carbon dioxide, and helium) in several expansion and compression configurations and in both recuperative and non-recuperative cases is studied against the pressure ratio for the design point. As a consequence, three configurations are selected looking for an improved overall thermal efficiency with respect to the pressure ratio. For these three configurations, an offdesign analysis is carried out in Sec. 5. Different output records are plotted throughout a day for the four seasons and carbon dioxide emissions are estimated. In addition, heliostats field efficiency is studied at the design point as well as in real fluctuating conditions.

\section{Thermodynamic model}

The overall system analyzed is a multi-stage gas turbine hybridized with a central solar tower in order to obtain a stable power output, independent of the solar irradiance conditions. A diagram of the considered system is shown in Fig. 1. The working fluid is first compressed by

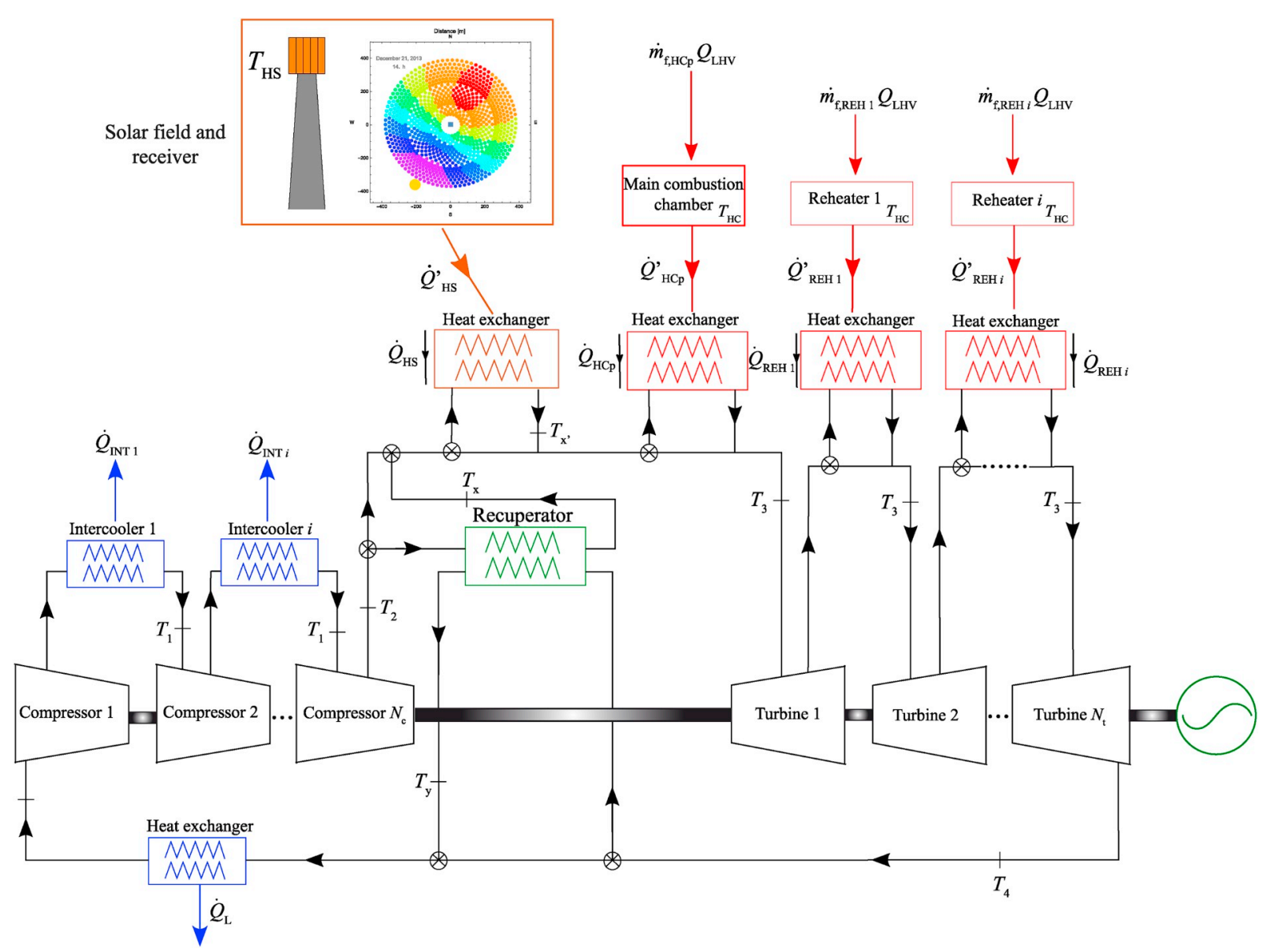

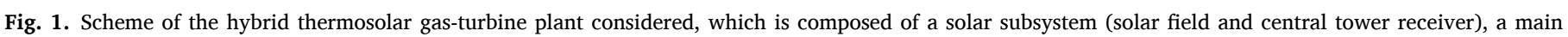

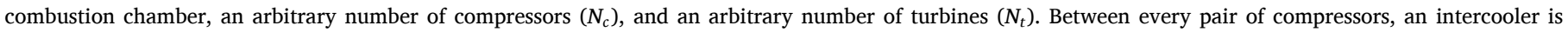
considered and, similarly, between every pair of turbines, an intermediate reheater is needed. 
means of a number $N_{c}$ of compressors with $N_{c} \quad 1$ intercoolers between them. Inlet temperature is assumed the same for all compressors. Afterwards, the fluid is heated by means of three different heat sources: a recuperator, a solar field, and a main combustion chamber. Then, $N_{t}$ expansion stages are next. It will be assumed that the inlet temperature for all turbines is the same, so $N_{t} 1$ reheaters are required. And, finally, the recuperator and a subsequent heat exchanger connected to the ambient release the necessary excess heat for starting the cycle again. This last heat exchanger is necessary because the model is considered as closed. So, the overall plant is composed of three subsystems: the solar subsystem, the combustion one, and the heat engine. The proposed thermodynamic model includes all the main losses and irreversibilities sources as depicted in Fig. 2.

In this section, the thermodynamic model of the considered plant is summarized since it has been recently detailed in Ref. [33]. Then, the attention is focused on the novel model aspects of this contribution.

\subsection{Overall efficiency}

The overall system thermal efficiency, $\eta$, can be expressed in terms of the net mechanical power, $P$, of the direct normal solar irradiance, $G$, of the heliostats field aperture area, $A_{a}$, of the lower heating value of the fuel, $Q_{L H V}$, and of the total fuel mass flow, $\dot{m}_{f}$, which is the addition of that consumed at the main combustion chamber and at the reheaters:

$\eta \frac{P}{G A_{a} \quad \dot{m}_{f} Q_{\mathrm{LHV}}}$

By defining the solar share, $f$, as the fraction of energy provided to the fluid that comes from the solar subsystem and by doing some thermodynamic calculations [34], the following expression for the overall thermal efficiency is achieved:

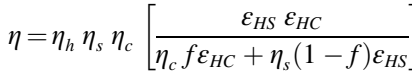

where $\eta_{h}$ represents the thermal efficiency of the heat engine, $\eta_{s}$ that of the solar subsystem (solar field and receiver), $\eta_{c}$ the efficiency of the combustion chamber, $\varepsilon_{H S}$ the effectiveness of the solar receiver as heat exchanger that transfers the solar heat input to the working fluid, and $\varepsilon_{H C}$ the effectiveness of the heat exchanger associated to the combustion chamber, that it is required because a closed Brayton cycle is being assumed. All formal definitions are explicitly shown in Ref. [33].

Another important parameter is the fuel conversion rate, $r_{e}$, or the performance relative to the energy input with an economical cost. The definition proposed by Heywood [35], when implemented in our model [34], yields to:

$r_{e} \frac{\eta \eta_{s} \eta_{h} \varepsilon_{H S}}{\eta_{s} \eta_{h} \varepsilon_{H S} \quad \eta f}$

For pure solar operation ( $\left.\dot{m}_{f} \quad 0\right), f \quad 1$, and $r_{e} \rightarrow \infty$ and for only combustion operation, $f \quad 0$, so $r_{e} \quad \eta$.

\subsection{Solar subsystem model}

\subsubsection{Solar field geometry}

The considered field is a circular heliostat field around the central tower, whose lowest part is always considered as the spacial reference origin, and its geometry is depicted at Fig. 3. The solar volumetric receiver is located atop of the tower and it is composed of several cylindrical tubes disposed symmetrically as the walls of a cylinder around a downing pipe in the centre of that cylinder.

The heliostat field is made up of several rows of heliostats and each heliostat is composed of a reflecting surface mounted on a support pedestal over the ground, with a two-axis tracking system that allows it to follow the Sun movements in the sky. The heliostat surface is a rectangular plane mirror, whose width-height ratio is $w_{r} L W / L H$. Heliostats are disposed in the field taking into account that their orientation changes with Sun tracking, as it can be observed in Fig. 4. Additionally, a safety distance between heliostats, $D H s$, must be

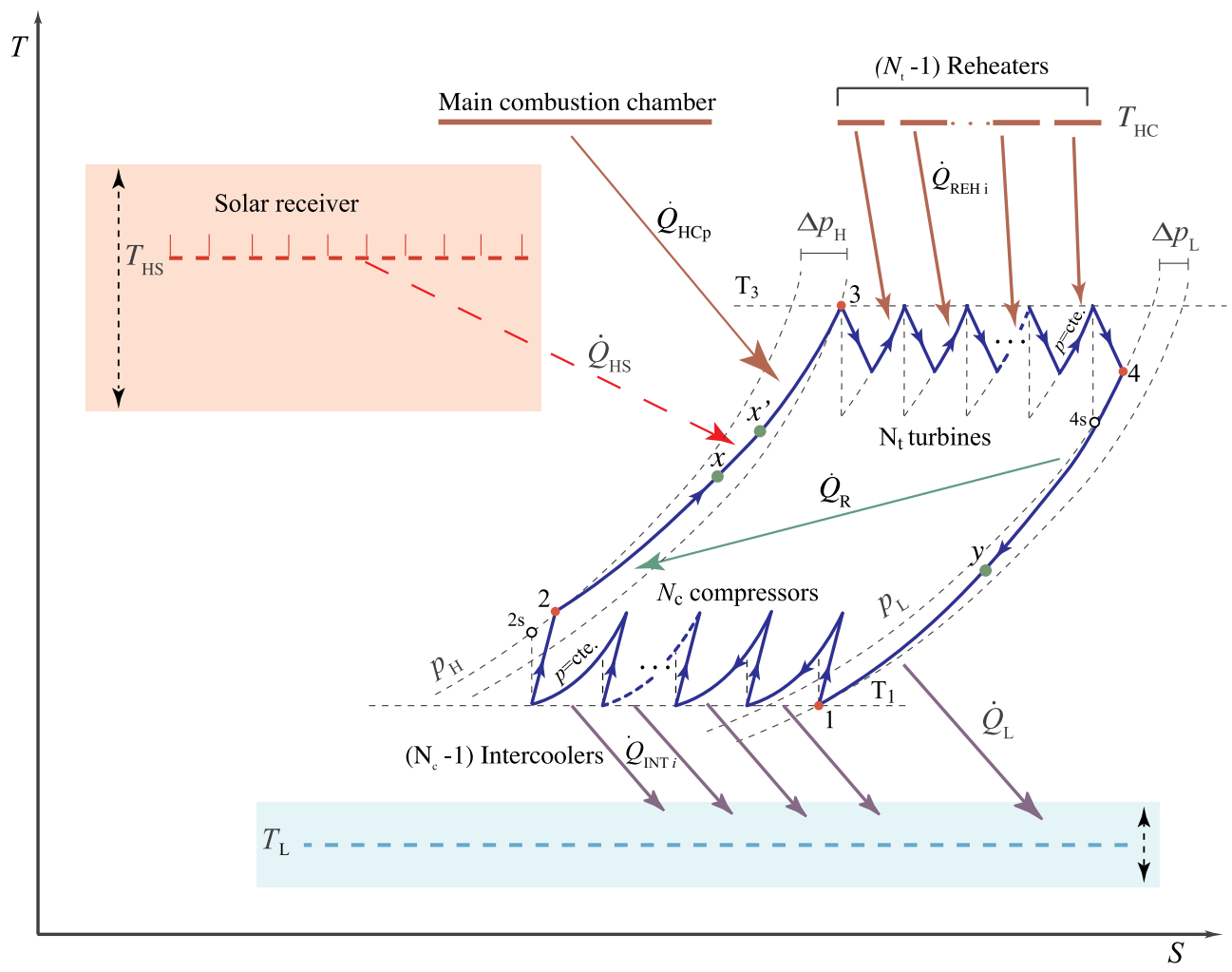

Fig. 2. Temperature-entropy diagram of the irreversible multistage Brayton cycle experienced by the working fluid in the considered plant. Solar receiver temperature, $T_{H S}$, and ambient temperature, $T_{L}$, are fluctuating parameters. 


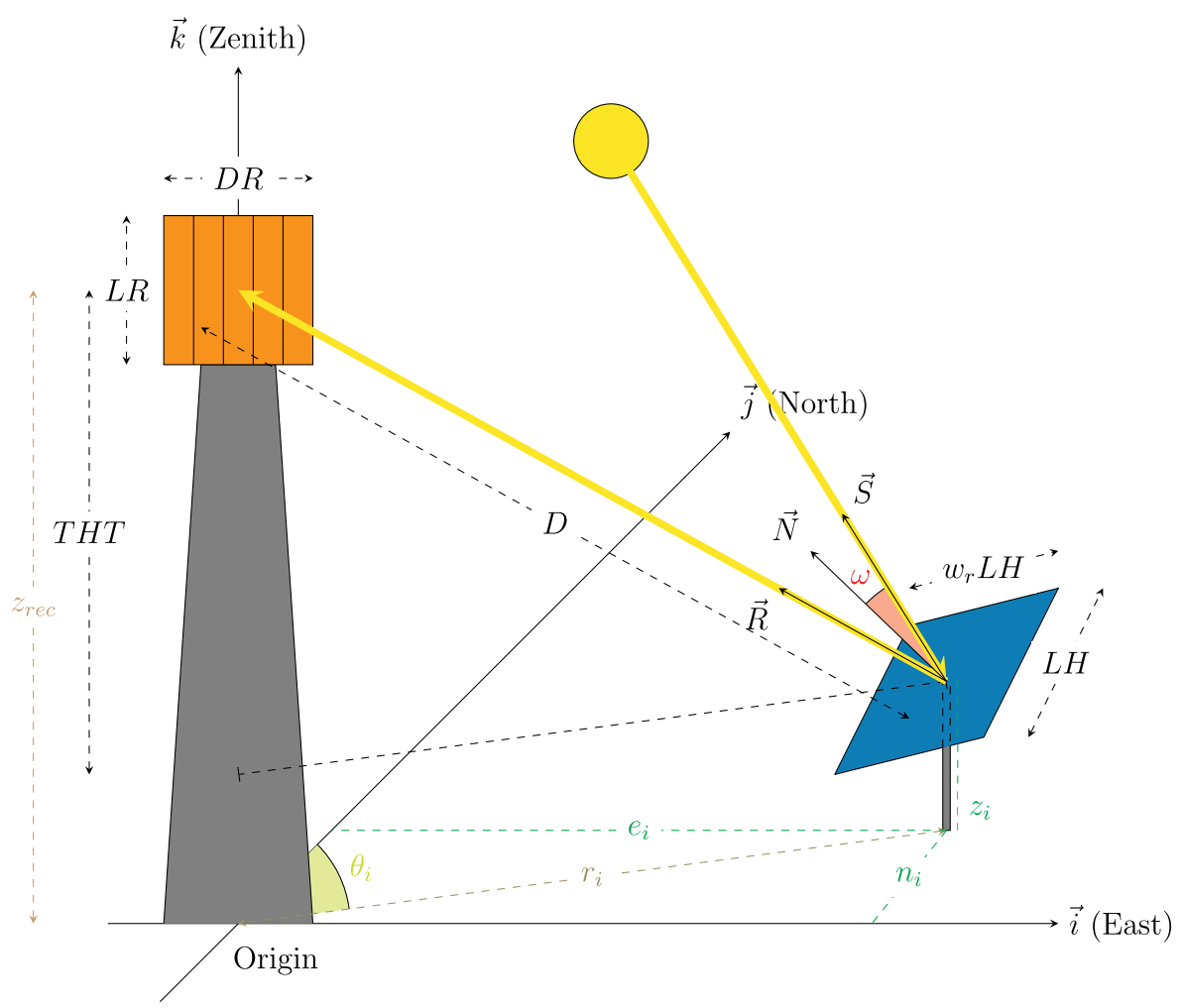

Fig. 3. Reference frame of the solar field, Sun incidence in the heliostat field, and reflection towards the solar receiver, assuming a plain ground [37].

considered [36].

Heliostats are disposed in an equidistant way over a circumference. Each one is associated to an angle $\theta_{i}$ (see Fig. 4). The heliostat field is divided into regions and rows. A region comprises one or more rows in which the increment of the azimuth angle, $\Delta \alpha_{T}$, is constant [36]. For a particular region, the farther the heliostats from the tower, the more separated they are. When this available separation is high enough for a new heliostat to be placed, then a new region starts. There are several field expansion techniques in the literature. Here, Campo code model was followed $[11,36]$. The starting point is the densest layout, that afterwards is expanded. Because of shadowing and blocking effects (explained below) there is a balance effect and optimum densities are found because field expansion advantages prevail over its disadvantages. In this work, heliostat densities were calculated as in a preliminar version of Campo code [36] with a simplified fixed blocking factor, and second, regions were completed up to find enough heliostats to approximately guarantee the desired turbine inlet temperature at design conditions.

\subsubsection{Solar field efficiency}

The optical efficiency of the whole field, $\eta_{0}$, is the average of the efficiency of each heliostat [36]:

$\eta_{0} \quad \bar{\eta}_{\text {hel }} \frac{\sum_{i=1}^{N H} \eta_{h e l_{i}}}{N H}$

where $\mathrm{NH}$ represents the total number of heliostats in the solar field. And the optical efficiency of each heliostat is defined as a product of losses factors [36]:

$\eta_{\text {hel }} \quad \cos \omega \cdot f_{b} \cdot f_{s h} \cdot f_{s p} \cdot f_{a t} \cdot \rho$

In this equation $\cos \omega$ stands for the cosine of the Sun radiation's incident angle, $f_{b}$ represents the blocking factor, $f_{s h}$ is associated with a shadowing factor, $f_{s p}$ refers to a spillage factor, $f_{a t}$ is related to an attenuation factor, and $\rho$ is the actual mirror reflectivity. These six losses parameters are represented in Fig. 5.

Cosine factor. The cosine effect constitutes the main factor of the optical efficiency [38]. In order to determine which is this incident angle of the Sun radiation in the heliostat surface, a study about the Sun-heliostat-receiver geometry should be accomplished by taking into account the law of specular reflection. This leads to an expression for $\omega$ that depends on each heliostat coordinates, receiver coordinates, and solar azimuth and altitude angles (see Fig. 3). An explicit equation for $\omega$ can be found in Ref. [36].

Blocking and shadowing factors. The blocking factor accounts for the energy loss because part of the reflected energy from a back heliostat can be stopped by an ahead one. On the other hand, the shadowing factor takes into account the energy loss when a heliostat projects a shadow on another heliostat, and then not all the surface of the last heliostat can reflect the sun radiation. The most complex elements affecting the optical efficiency are precisely these blocking and shadowing factors [38]. Therefore, it is not easy to express them in an analytical way and simulate them accurately, so it is not unusual to take these factors as constant $[39,40]$.

Spillage factor. The power delivered by each heliostat to the receiver is the integral over the receiver contours of the corresponding flux density function. The fraction outside receiver boundaries is called spillage. In this work it is assumed the formulation by Collado [7] in which the spillage factor depends on the dimensions of the receiver, heliostat area, and the effective dispersion of the sun shape on the receiver plane. Explicit equations can be found in Ref. [7]. Other formulations as the one used in HFLCAL also consider dispersions associated to mirror surface errors and tracking errors $[10,41]$. This makes the spillage factor depend on each heliostat position with respect to the receiver, leading to calculations computationally more expensive. Both formulations were checked within our overall model and no significant differences found, so the analytical model from Ref. [7] was assumed.

Attenuation factor. The attenuation factor, $f_{a t}$, takes into account the energy dissipation due to the energy absorption of the air molecules between the heliostats and the receiver. Clearly, this factor depends on 


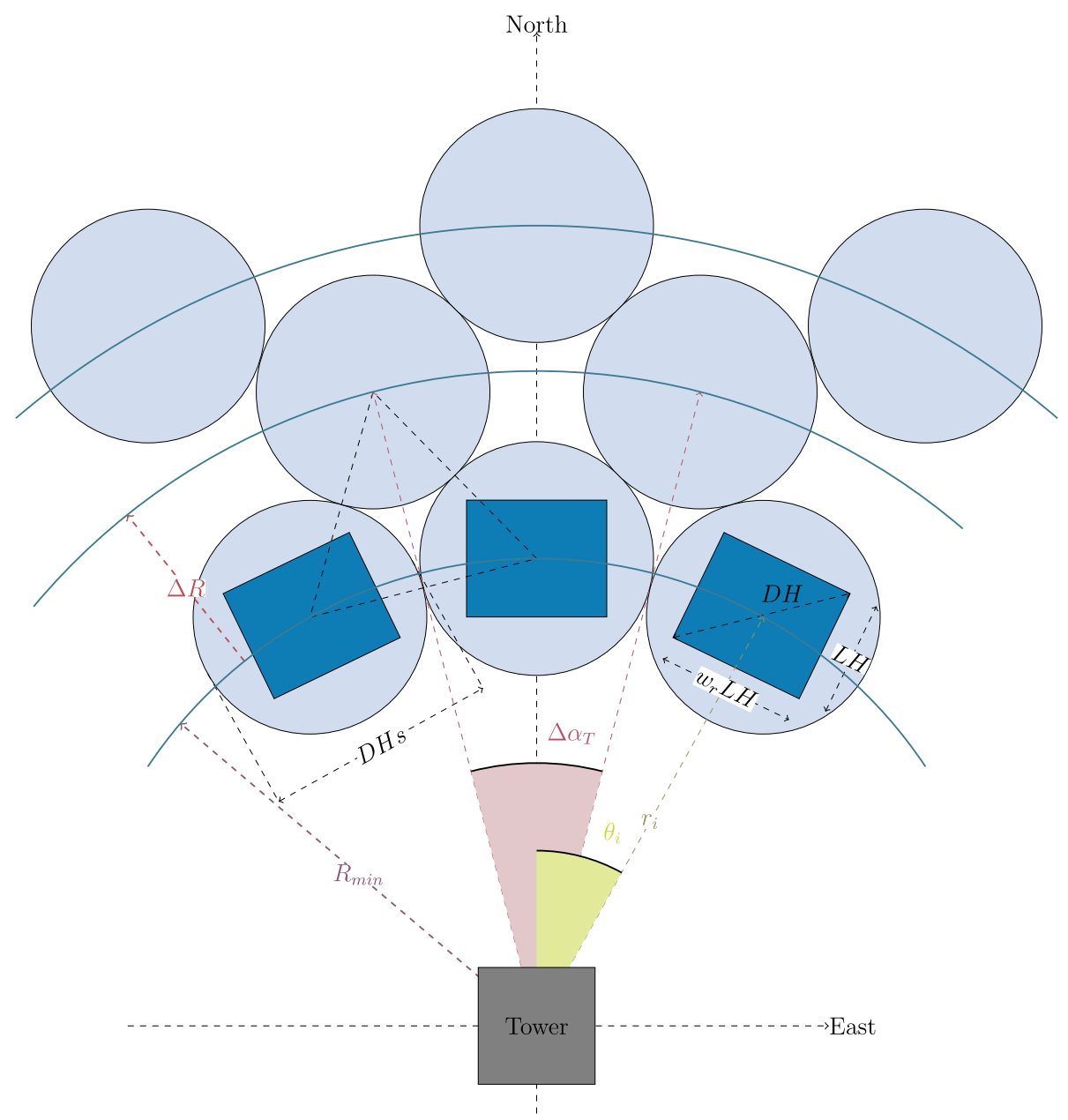

Fig. 4. Radial staggered distribution for the heliostats field [7].

the distance between the centre of the heliostat and the aim point in the receiver, $D$ [42]. So, it varies with the particular heliostat and, thus, for great solar fields, differences in attenuation are more significant than for smaller fields. It is usual to take an empirical formula for $f_{a t}$ in terms of $D$. In this work the equations by Leary and Hankins [43] for distances below $1 \mathrm{~km}$ and Schmitz et al. [10] for longer distances are assumed.

Mirror reflectivity. The actual reflectivity, $\rho$, of a mirror can be modeled as the product of two factors: the nominal reflectivity, $\rho_{n}$, and the nominal cleanliness, $C_{n}, \rho \quad \rho_{n} \cdot C_{n}$ [41]. The importance of the actual reflectivity is not just related to the efficiency of the heliostat; but, in fact, it is also a function of the maintenance cost of the field since the nominal cleanliness depends on plant conservation.

As a summary, it can be noted that only the cosine factor and the attenuation factor depend on the particular heliostat, the other four factors are independent of the heliostat. So, in the average optical efficiency (see Eq. (4)), just the cosine and the attenuation factors are inside the summation, the other four terms are common factors.

\subsubsection{Solar subsystem efficiency}

In addition to all the aforementioned losses associated with the solar energy transfer from the heliostats to the receiver, another energy losses in the solar subsystem must be analyzed. These are the ones related to the heat transfer out of the receiver because of conduction, convection, and radiation. In this way, the solar subsystem efficiency is $[33,44]$ :

$\eta_{s} \quad \eta_{0} \quad \frac{1}{G C} \alpha \sigma T_{H S}^{4} \quad T_{L}^{4} \quad \bar{U}_{L} T_{H S} \quad T_{L}$ receiver surface, $\sigma$ is the Stefan-Boltzmann constant, $\bar{U}_{L}$ corresponds to an overall conduction and convection heat transfer coefficient, $T_{H S}$ is the solar collector temperature and $T_{L}$, with the ambient temperature.

The heat flux actually absorbed by the working fluid is: $\left|\dot{Q}_{H S}\right|$ $\varepsilon_{H S} G A_{a} \eta_{s}$, where $\varepsilon_{H S}$ refers to the effectiveness of the solar receiver, considered as a heat exchanger.

\subsection{Combustion subsystem model}

The model for the heat transfer from the main combustion chamber and the reheaters to the working fluid (see Fig. 1) includes the nonideality of combustion and the losses in the combustion chamber, but also the losses in the associated heat exchanger. This applies both for the main combustion chamber and for all the reheaters. In this way, the heat rate transferred from the main combustion chamber and the reheaters to the working fluid can be expressed as:

$$
\dot{Q}_{\mathrm{HCp}} \quad\left|\dot{Q}_{\text {reh }}\right| \quad \eta_{c} \varepsilon_{H C} Q_{\mathrm{LHV}} \quad \dot{m}_{H C p} \sum_{i=1}^{N_{t} 1} \dot{m}_{R E H i}
$$

where $\dot{m}_{\mathrm{HCp}}$ is the fuel consumption rate at the main combustion chamber, $\dot{m}_{R E H i}$ refers to the fuel mass flow entering the reheaters, $\varepsilon_{H C}$ is the effectiveness of the heat exchangers (assumed equal), $\eta_{c}$ combustion efficiency (also assumed the same), and $Q_{\mathrm{LHV}}$ the fuel lower heating value.

where $C$ is the concentration ratio, $\alpha$ refers to the emissivity of the 


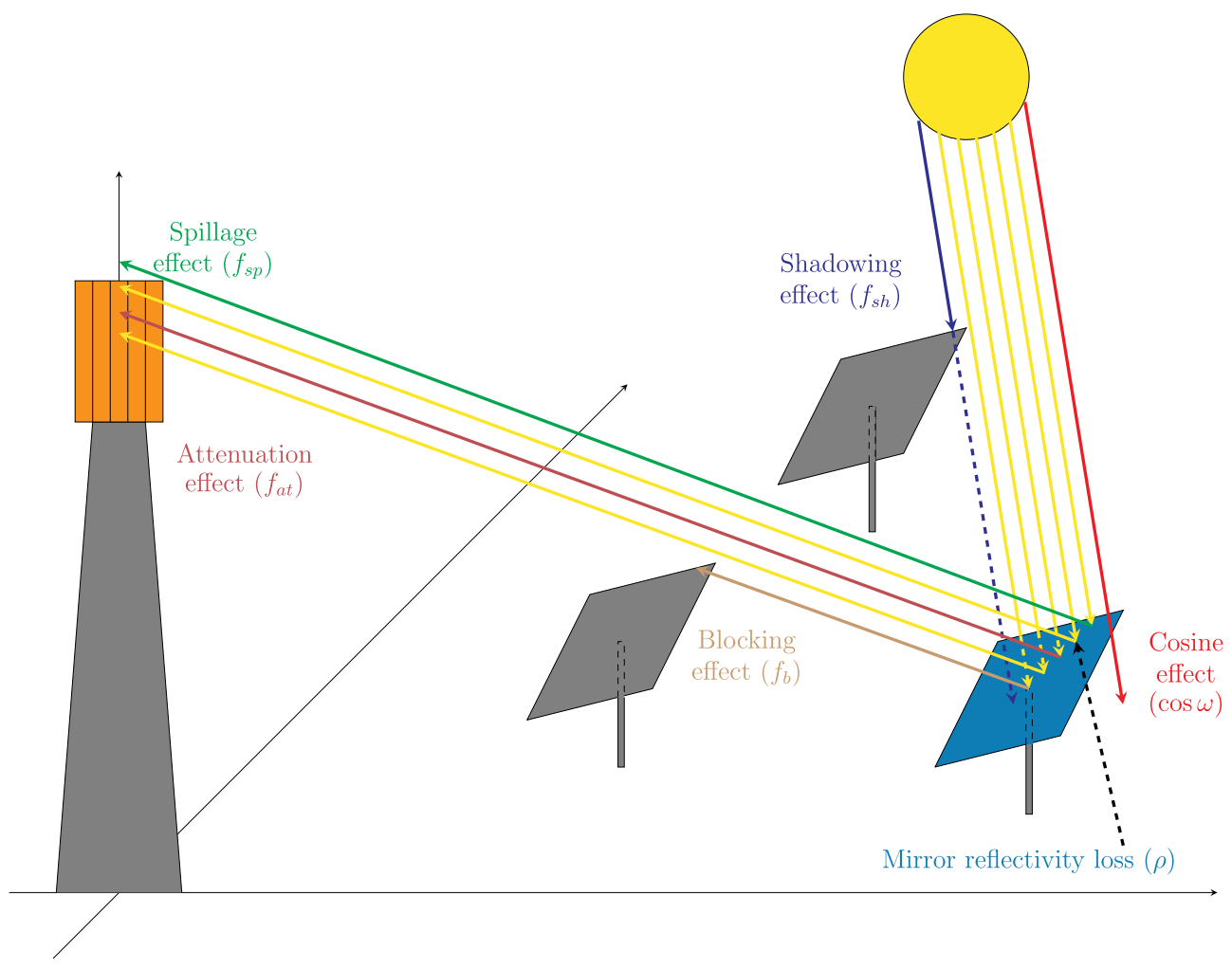

Fig. 5. Energy losses factors of the heliostat efficiency.

\subsection{Multi-stage Brayton cycle model}

For the multi-stage Brayton power block it is considered a working fluid behaving as an ideal gas with temperature dependent specific heats. Details on the assumptions for the losses or irreversibilities considered are summarized in Appendix A as well as the explicit equations for temperatures $T_{2}$ and $T_{4}$ in terms of the geometric and irreversibilities parameters. All other cycle temperatures can be calculated from those $[33,45]$. The power output provided by the plant, $P$, and its thermal efficiency, $\eta_{h}$, can be calculated through the heat rates by means of the cycle temperatures in terms of all the irreversibilities and geometric parameters: $P \quad\left|\dot{Q}_{H}\right| \quad\left|\dot{Q}_{L}\right|$ and $\eta_{h} \quad P /\left|\dot{Q}_{H}\right|$. The total heat input rate absorbed by the working fluid, $\left|\dot{Q}_{H}\right|$, can be calculated as:

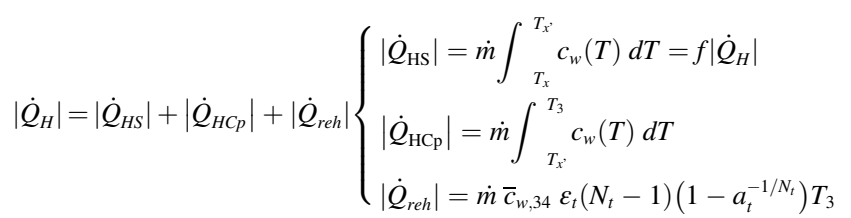

And the heat released by the working fluid to the ambient, $\left|\dot{Q}_{L}\right|$, is:

$$
\left|\dot{Q}_{L}\right| \quad \dot{m} \int_{T_{1}}^{T_{y}} c_{w} T d T \quad \dot{m} \frac{\bar{c}_{w, 12}}{\varepsilon_{c}} N_{c} \quad 1 \quad a_{c}^{1 / N_{c}} \quad 1 \quad T_{1}
$$

Finally, it is important to stress that, as a consequence of the assumptions made in this model for the sequence of heat absorption processes, the following conditions for temperatures hold (see Fig. 2):

$$
\begin{aligned}
& \begin{array}{lll}
T_{3} & T_{x^{\prime}} & T
\end{array} \\
& T_{H S} \quad T_{x} \\
& T_{H C} \quad T_{x^{\prime}}
\end{aligned}
$$

\section{Numerical implementation and working fluids}

The thermodynamic model of the Brayton cycle was previously validated [33,34] by comparing with the SOLUGAS Project [25]. This project, developed by Abengoa Solar near Seville (Spain), tested a Brayton hybrid turbine in a pre-commercial scale of about $5 \mathrm{MWe}$. The present work is focused on the optimization and estimation of output records for a larger plant, in a commercial scale of about $20 \mathrm{MW}$. To achieve that aim the main system dimensions are taken from a commercial plant called GEMASOLAR [18] working on that power output range although within a different concept: Rankine cycle with molten salt storage. This plant includes a circular heliostat field and a cylindrical receiver. Details on the numerical parameters to run the model and its validation are contained in Appendix B.

In this work, a thermodynamic study of the plant performance for different working fluids is accomplished looking for better output records. However, the necessary study of the technical features of the devices is not carried out here. As stated by Olumayegun et al. [46], the most usual working fluids developing closed cycles in gas turbines are air, nitrogen, carbon dioxide, helium, and other noble gases and also gas mixtures. In this study, we consider the first four gases as working fluids. The widest experience in the design and operation of these cycles is associated to air cycles. However, the associated turbine inlet temperatures are high. Nitrogen has very similar characteristics than air but the curve for constant pressure specific heat is slightly different, specially for temperature between 300 and $900 \mathrm{~K}$. The advantages of helium are the low pressure losses and its good heat transfer coefficient. But its design experience is smaller and its turbine inlet temperatures are also high. Finally, for the carbon dioxide, solar applications for supercritical $\mathrm{CO}_{2}$ are being studied in order to reduce the work required by the compressor $[33,47]$, but researches with subcritical $\mathrm{CO}_{2}$ are still scarce.

In the particular case of the pressure and temperature intervals experienced by the fluids, three of them develop subcritical cycles: dry air, nitrogen $\left(\mathrm{N}_{2}\right)$ and carbon dioxide $\left(\mathrm{CO}_{2}\right)$; meanwhile, the other one, helium ( $\mathrm{He}$ ), develops a transcritical cycle (see Fig. 4 of [33]). Table 1 
collects some thermodynamic data for these fluids, including critical pressure and temperatures. The approximate Brayton cycles developed by each fluid in $p \quad T$ diagrams were presented in Fig. 4 of [33]. In all cases, the specific heats are considered as temperature dependent. Polynomial fittings were taken from Ref. [48]. The explicit form of the polynomials can be found in Table 1 of [33]. It is interesting the fact that the average specific heat of the helium is four times the ones of the other fluids, as it can be seen in Table 1 .

\section{On design pre-optimization}

In this section, numerical plant output records are analyzed for different configurations and different working fluids at the design point (see Table 4 in Appendix B). The efficiency of each heliostat is computed and represented in Fig. 6 . It has been proven that the highest efficiency is related to the heliostats opposite to the Sun [42]; therefore, to the North heliostats at design point (noon). The average efficiency of the heliostats field at these conditions is 0.4961 .

The evolution of the overall thermal efficiency, the fuel conversion rate, the power output, the solar collector temperature, and the solar share with the pressure ratio is depicted for the aforementioned working fluids and for different configurations in Figs. 7-11. The analyzed cases correspond to the one-turbine and one-compressor configuration $(N$ $1)$, both recuperative and non-recuperative; and to the two $\left(\begin{array}{ll}N \quad 2\end{array}\right)$, three $\left(\begin{array}{ll}N & 3\end{array}\right)$, and infinite expansion and compression stages $(N \rightarrow \infty)$ only in the recuperative mode. The cases of infinite stages are represented in order to visualize the maximum values that the variables could take, as a limit case.

The overall thermal efficiency in this study (Fig. 7) behaves in a similar way that for a smaller plant, SOLUGAS of about $5 \mathrm{MW}[25,33]$ (note that in Ref. [33] heliostat field efficiency was calculated in an approximate averaged way). At the light of this figure, it can be concluded that only for some fluids ( $\mathrm{He}$, air, and $\mathrm{N}_{2}$ ) and $N \quad 1$ overall efficiency has a maximum in terms of $r_{p}$, i.e., there is an optimum pressure ratio. In all other cases, curves increase monotonically, so larger pressure ratios lead to larger overall efficiencies. Numerical values are larger for He because of the reasons that will be detailed later on. For $N \quad 1$ and small values of $r_{p}$ overall efficiency in the recuperative case is larger than in the non-recuperative one for all fluids except $\mathrm{CO}_{2}$. In the latter recuperation is advantageous in all the surveyed interval of pressure ratios.

In addition, curves of the fuel conversion rate, $r_{e}$ (see Fig. 8), for He resemble those for SOLUGAS (see Fig. 10 in Ref. [33]). However, for the other three working fluids, these fuel conversion rate curves are quite different. Now, $r_{e}$ decreases with the pressure ratio for any number of compression/expansion stages in an approximately exponential way, very fast up to values of $r_{p} \simeq 4 \quad 5$ (depending on the multi-stage configuration) and more slowly afterwards. This change is due to the new scaling up of the plant. Numerically, high values for $r_{e}$ are found (about 4 times larger than for SOLUGAS) except for He. For $N \quad 1$ non-recuperative layout, $r_{e}$, always increase with $r_{p}$ (also except for $\mathrm{He}$ where there is a wide plateau in the interval $r_{p} \simeq 10 \quad 20$ ).

In the case of the power output, $P$, evolutions are very similar to

Table 1

Some thermodynamic properties of the four considered working fluids: molecular weight $(M)$, critical temperature and pressure $\left(T_{c}\right.$ and $p_{c}$ respectively) and mean values of the constant pressure specific heat $\left(\bar{c}_{w}\right)$ and adiabatic coefficient $(\bar{\gamma})$.

\begin{tabular}{lllll}
\hline & $\mathrm{He}$ & $\mathrm{N}_{2}$ & Dry air & $\mathrm{CO}_{2}$ \\
\hline$M(\mathrm{~g} / \mathrm{mol})$ & 4.00 & 28.01 & 28.97 & 44.01 \\
$T_{c}(\mathrm{~K})$ & 5.1953 & 126.19 & 132.84 & 304.13 \\
$p_{c}(\mathrm{bar})$ & 2.2761 & 33.958 & 38.501 & 73.773 \\
$\bar{\gamma}$ & 1.6667 & 1.3561 & 1.3458 & 1.1986 \\
$\bar{c}_{w}[\mathrm{~J} /(\mathrm{g} \mathrm{K})]$ & 5.1965 & 1.1354 & 1.1202 & 1.1587 \\
\hline
\end{tabular}

those of overall efficiencies as it can be observed in Fig. 9. Only for He, $\mathrm{N}_{2}$, and air and for the single stage plant configuration power output displays a (flat) maximum as a function of $r_{p}$.

Another interesting variable evolution is the solar collector temperature, depicted in Fig. 10. There is a noticeable difference between nonrecuperative and recuperative configurations. In the first case, the temperature rises with the pressure ratio and, in the second one, it decreases. It should be also highlighted that the temperature increases when the number of expansion and compression stages does. It is of vital importance to control the solar collector temperature since the receiver materials themselves impose a temperature limit that could not be exceeded. Then, plant configurations associated with lower temperatures are more interesting from the viewpoint of the materials for the receiver. The lowest temperatures are predicted for $\mathrm{He}$ in the nonrecuperative single stage case for low pressure ratios. In this case, the tubular receiver associated with the circular solar field should withstand temperatures below $1000 \mathrm{~K}$ for $r_{p}<12$. Temperatures for dry air and the other fluids in the same non-recuperative single stage case are all over $1000 \mathrm{~K}$. For all multi-stage configurations smaller temperatures are required as $r_{p}$ increases.

For case of $\mathrm{He}$, as solar collector temperatures are smaller, the choice of a tubular receiver in a circular field could be feasible. However, when working with the other two configurations associated to higher temperatures, current tubular receivers are not the best option. Thus, the tubular receiver and circular field should be replaced by a cavity receiver with a wedge field meanwhile the limits of temperatures are surpassed $[13,15,17]$.

Table 2 summarizes the maximum values of the overall thermal efficiencies for the four working fluids and for different numbers of turbines and compressors (assumed equal). Furthermore, the corresponding pressure ratio and the relative growth of the overall efficiency, of the fuel conversion rate, and of the power output are displayed. Comparison is always with respect to the design pressure ratio of the gas turbine $\left(r_{p, D P}\right.$ 23.4). For the dry air single recuperative configuration, an increase of almost $7 \%$ in the overall thermal efficiency could be reached by reducing the pressure ratio to the half. As it can be also deduced from Fig. 7, the global efficiency for He in the single recuperative case can be highly increased if the pressure ratio is drastically reduced. Note that in some multi-stage configurations a positive increase or $\eta$ corresponds to a decrease of $r_{e}$ because of the corresponding increase in fuel consumption.

The behavior of solar share, Fig. 11, is easy to understand from the evolution of solar collector temperatures (see Fig. 10). Globally, the numerical values of $f$ are smaller for He because $T_{H S}$ are lower and so, more fuel is to be burned to achieve turbine inlet temperature. $\mathrm{Nu}$ merical differences between numerical values for He and the other fluids are important as seen in the figure. The evolution with the number of stages is identical for all fluids. As more compression/expansion stages are considered, collector temperature decreases and so, more fuel is burned in the reheaters. So, the solar share decreases with the number of stages. In respect to the evolution with the pressure ratio, for recuperated configurations $T_{H S}$ decreases with $r_{p}$, and similarly does $f$. In this case, the better configurations to take advantage of the solar input are those with small pressure ratios. For the single stage, non-recuperated configuration, both $T_{H S}$ and $f$ increase with $r_{p}$.

The choice of possible optimum configurations is carried out taking into account three features: high overall thermal efficiencies, low solar collector temperatures, and large solar share (although the last two ones are not independent). Three particular configurations have been selected: $\alpha$, dry air single non-recuperative $\left(\eta \quad 0.18, T_{H S} \quad 1300 \mathrm{~K}, f\right.$ $0.60) ; \beta$, dry air two compression and expansion stages recuperative ( $\eta \quad 0.28, T_{H S} \quad 1420 \mathrm{~K}, f \quad 0.40$ ); and $\gamma$, He single non-recuperative configuration ( $\left.\eta \quad 0.32, T_{H S} \quad 925 \mathrm{~K}, f \quad 0.16\right)$. The off-design analysis in the next section will be performed on these cases.

A Sankey diagram is represented for each of these configurations (see 


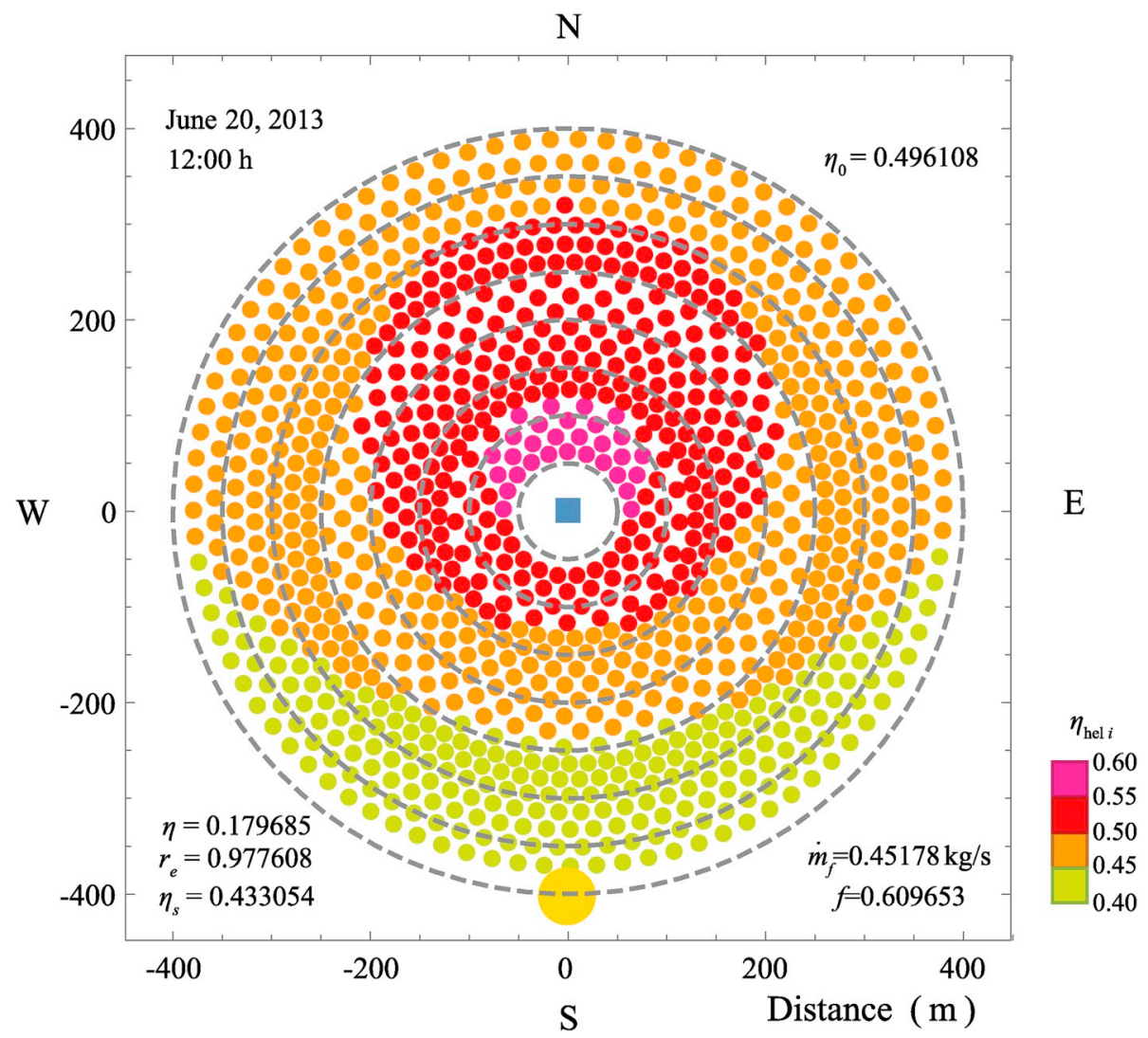

Fig. 6. Heliostat efficiencies at design conditions.
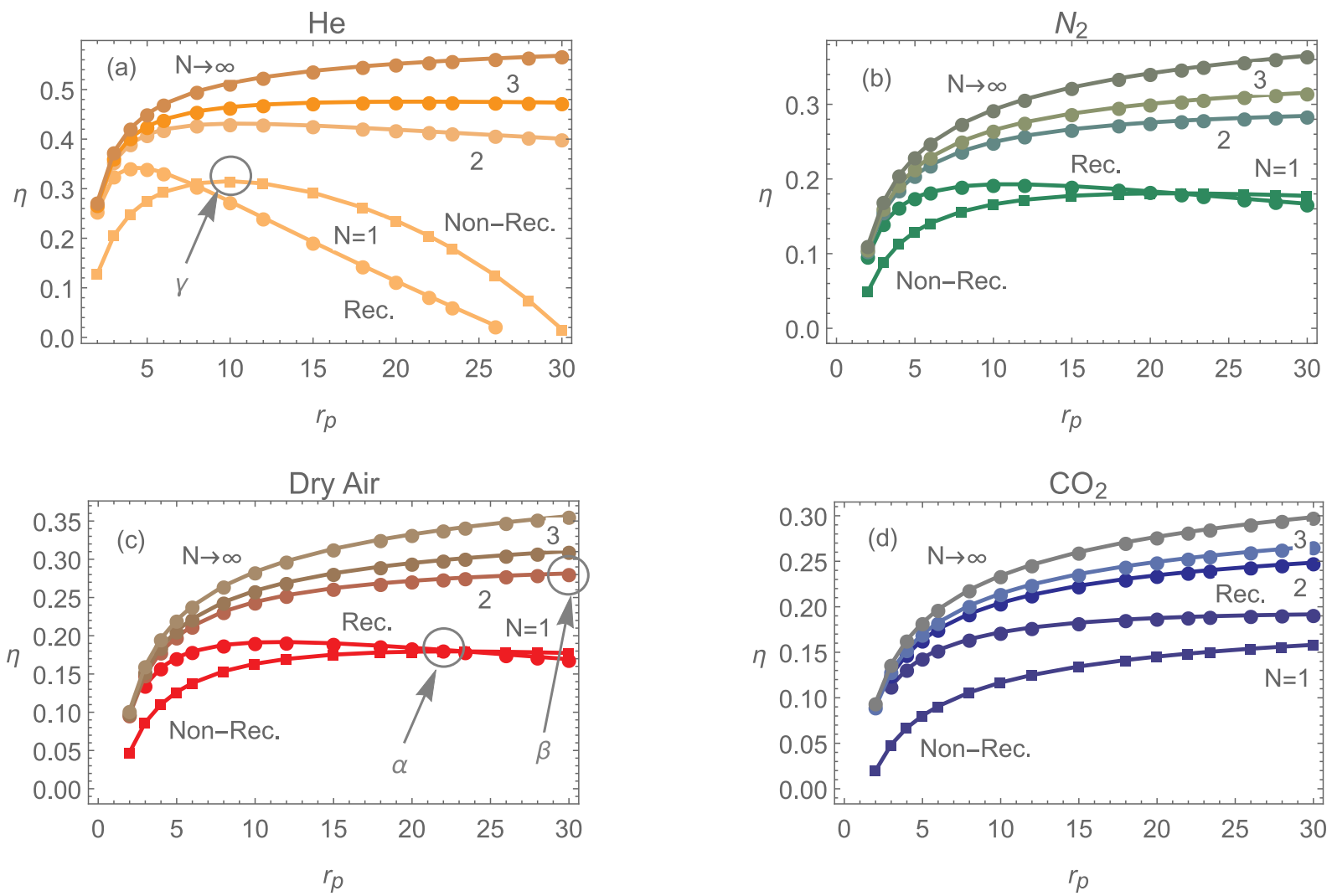

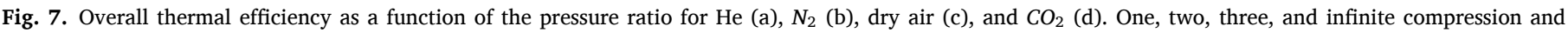

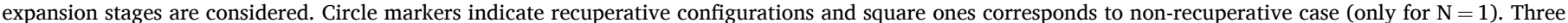
particular configurations, denoted $\alpha, \beta$, and $\gamma$, are highlighted (as discussed hereinafter in the text). 

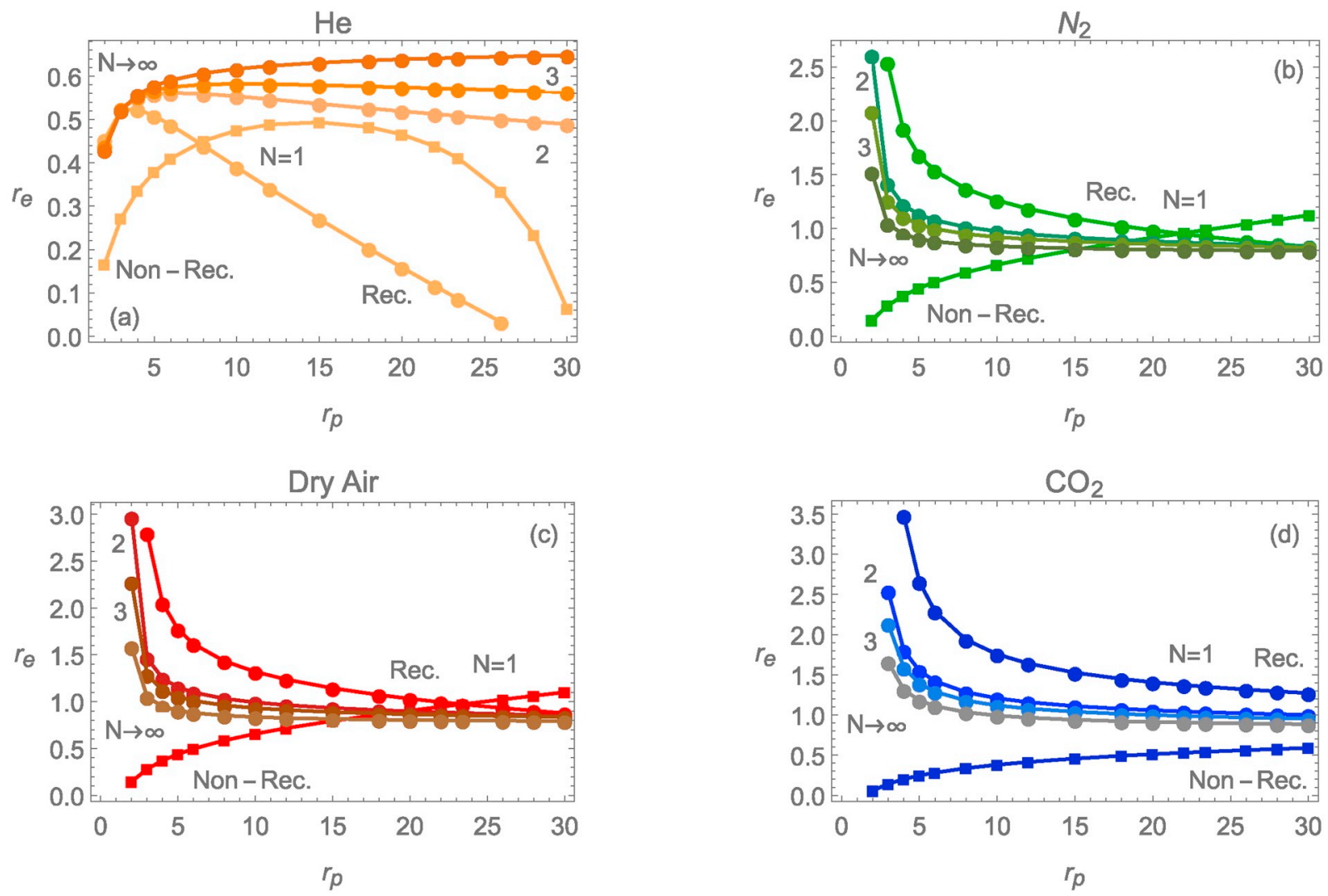

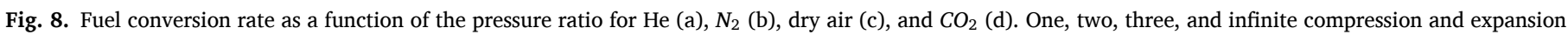
stages are considered.
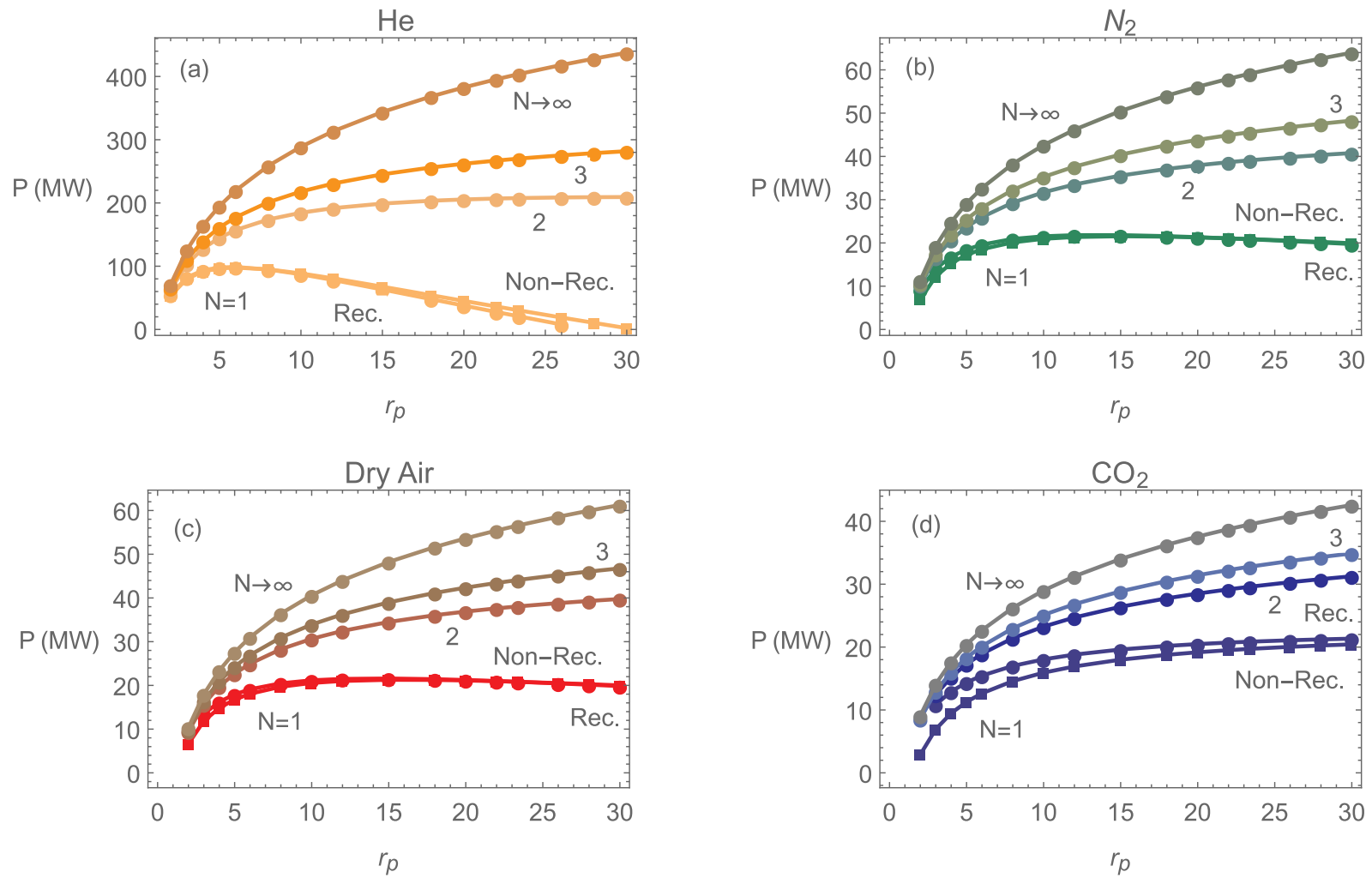

Fig. 9. Power output as a function of the pressure ratio for $\mathrm{He}$ (a), $\mathrm{N}_{2}$ (b), dry air (c), and $\mathrm{CO}_{2}$ (d). 

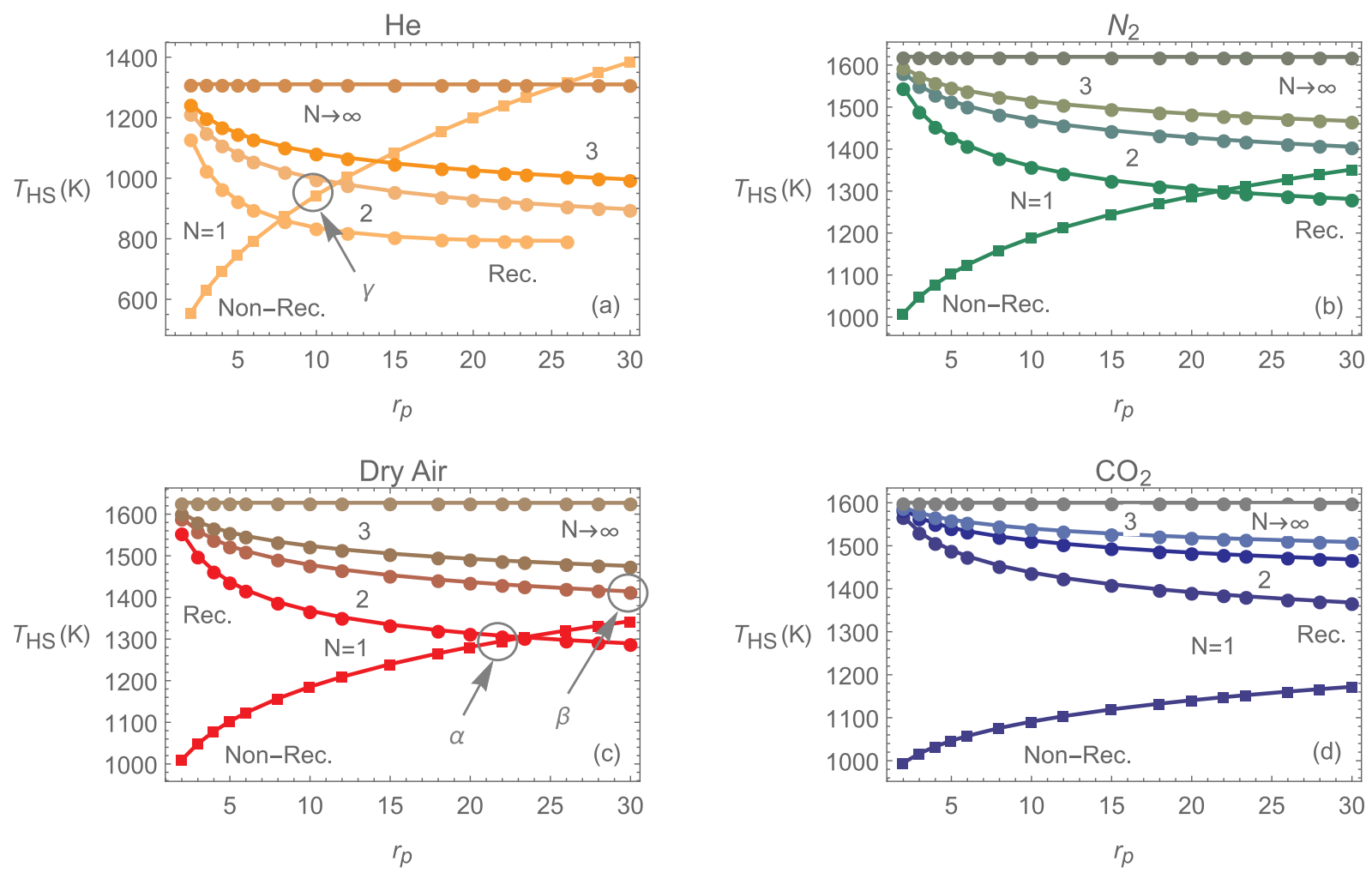

Fig. 10. Solar collector temperature as a function of the pressure ratio for $\mathrm{He}$ (a), $\mathrm{N}_{2}$ (b), dry air (c), and $\mathrm{CO}_{2}$ (d).
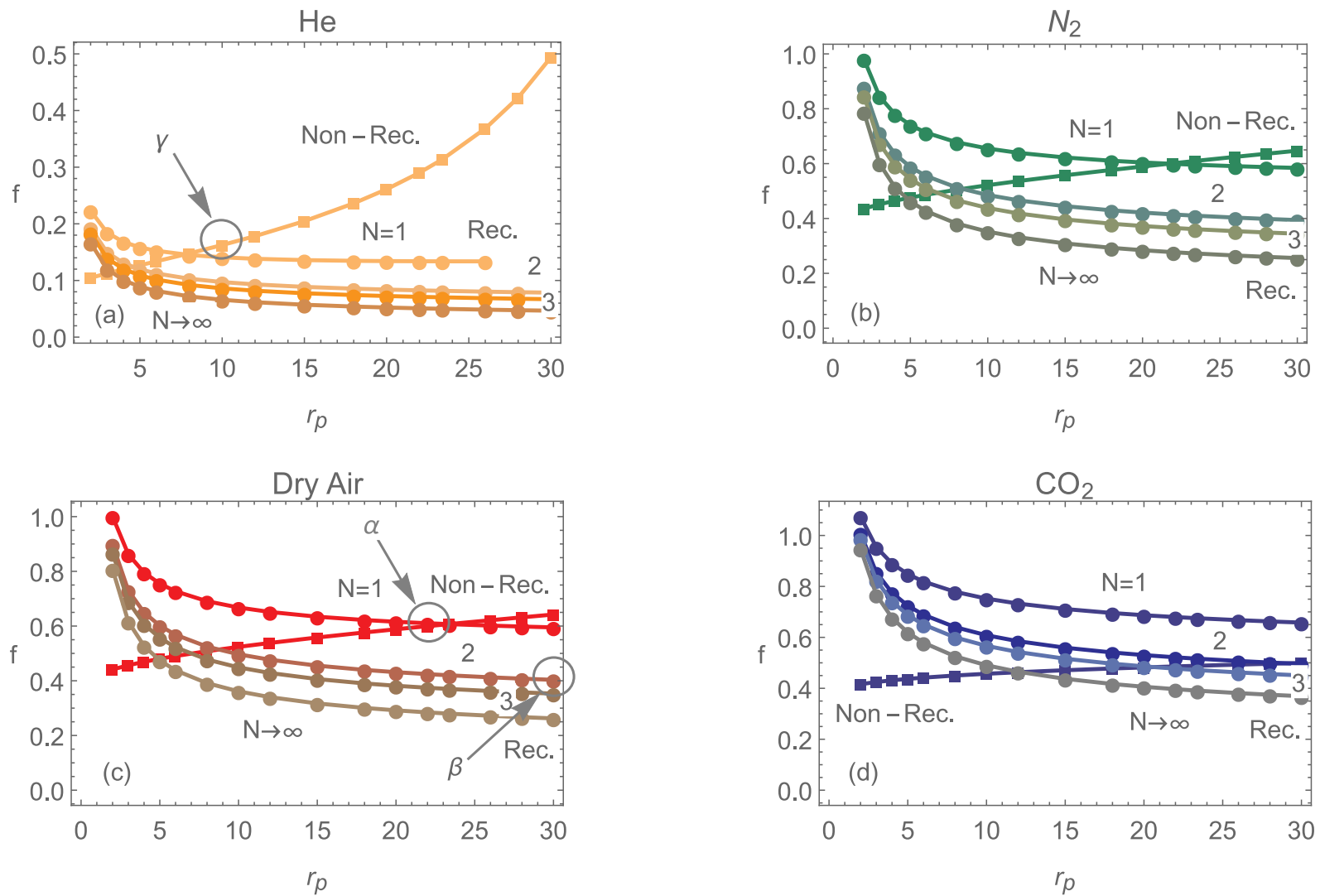

Fig. 11. Solar share as a function of the pressure ratio for $\mathrm{He}(\mathrm{a}), \mathrm{N}_{2}$ (b), dry air (c), and $\mathrm{CO}_{2}$ (d). 
Table 2

Relative variations of output records achieved by choosing the optimum pressure ratio regarding overall thermal efficiency in each case with respect to the design pressure ratio of the gas turbine (dry air, $r_{p, D P} \quad 23.4$, recuperative) are shown. The number of compression and expansion stages $(N)$, the maximum overall efficiency, $\eta_{\max }$, its corresponding pressure ratio, $r_{p, \eta_{\max }}$, and relative improvements of overall thermal efficiency, $\Delta \eta$, fuel conversion rate $\Delta r_{e}$, and power output, $\Delta P$, are included.

\begin{tabular}{llllll}
\hline $\mathrm{N}$ & $\eta_{\max }$ & $\mathrm{r}_{\mathrm{p}, \eta_{\max }}$ & $\Delta \eta \%$ & $\Delta \mathrm{r}_{\mathrm{e}} \%$ & $\Delta \mathrm{P} \%$ \\
\hline Dry air & & & & & \\
1 & 0.191862 & 12 & 6.91837 & 27.3001 & 3.173 \\
2 & 0.28144 & 30 & 56.8371 & 12.3100 & 90.98274 \\
3 & 0.310565 & 30 & 73.0677 & 13.9978 & 124.628 \\
& & & & & \\
1 & 0.192919 & 10 & 7.50699 & 30.0217 & 3.44557 \\
2 & 0.284472 & 30 & 58.5266 & 13.8591 & 95.8396 \\
3 & 0.315487 & 30 & 75.8101 & 14.9183 & 131.873 \\
& & & & & \\
1 & 0.191657 & 30 & 6.80423 & 31.0573 & 2.50332 \\
2 & 0.24847 & 30 & 38.4641 & 3.10643 & 50.1376 \\
3 & 0.266093 & 30 & 48.2845 & 1.67984 & 67.595 \\
He & & & & & \\
1 & 0.342435 & 4 & 90.8272 & 46.0711 & 349.6 \\
2 & 0.4313 & 10 & 140.349 & 42.9728 & 786.468 \\
3 & 0.475587 & 22 & 165.029 & 41.094 & 1182.7 \\
\hline
\end{tabular}

Fig. 12). Energy inputs are those coming from the solar contribution and from combustion. In each plot, the total heat input rate is normalized to unity. In the two-stage example (Fig. 12(b)) two terms contribute to fuel combustion, that from the main combustion chamber, $\dot{m}_{f, H C p} Q_{L H V}$, and that from the reheater in between turbines, $\dot{m}_{f, R E H} Q_{L H V}$. It is noteworthy that $\dot{m}_{f R E H} Q_{L H V}$ is larger (about 3.7 times larger). This is because the heliostat field at design conditions is capable to increase the fluid temperature to a value $T_{x}$ ' not far from the turbine inlet temperature, $T_{3}$ (see Fig. 2). On the other hand, the reheater has to increase the temperature from $T_{4}$ (that is quite below $T_{x}^{\prime}$ ) to $T_{3}$, so a comparatively larger heat input is required. Cycle temperatures will be discussed in detail below.

These diagrams include also the main losses in each subsystem with this notation: $\dot{Q}_{0}$ are the optical losses in the heliostat field, $\dot{Q}_{l}$ are the heat losses in the receiver, $\dot{Q}_{i H S}$ are the losses in the heat transfer from the receiver to the working fluid of the turbine, $\dot{Q}_{C}$ are the losses in the combustion chamber, and $\dot{Q}_{i H C}$ are the losses in the heat exchanger associated to the combustion chamber. In all cases it is apparent that the main losses comes from the optical losses in the heliostat field. In the case of He, solar contribution is small and so, optical losses are small. In consequence power output (and also overall efficiency because heat input is normalized) is large. On the other hand, for dry air mono-stage recuperative configuration, solar contribution represents more than $80 \%$ of the total heat input. So, as a conclusion, in all configurations where the relative weight of the solar subsystem is large, optical losses are also large and the overall efficiency is smaller. A similar reasoning also explains the different scales in the values of the fuel conversion efficiency, $r_{e}$, displayed in Fig. 8.

\section{Off-design analysis}

In this section, a daily and a seasonal study is carried out by selecting four different days at the beginning of the four seasons. Solar field configuration was set at the design point (Fig. 6). Now, in off-design conditions, solar field for the four seasons is computed at any hour. For instance, Fig. 13, shows the efficiency of the heliostats and the averaged one at a particular hour (14:00 h UTC) for any season. The highest efficiency is found for summer and the smallest, for winter (relative increase in summer with respect to winter is about 13.1\%) while autumn and spring lead to intermediate values. During summer no
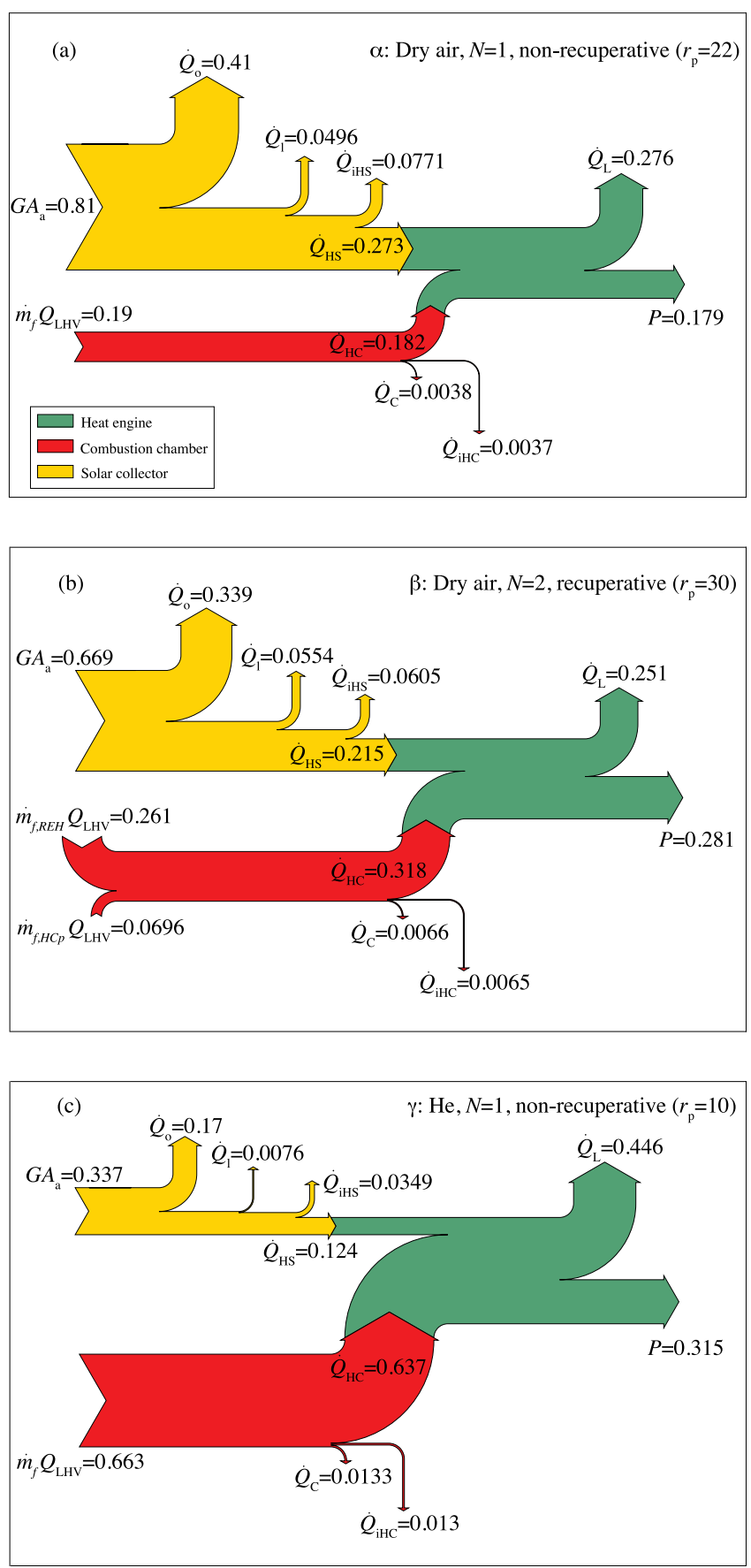

Fig. 12. Sankey diagrams for heat flows in the plant at the design point for three selected configurations, $\alpha, \beta$, and $\gamma$. Heat input is normalized to unity in each case. (a) Dry air, non-recuperative, single stage; (b) Dry air, recuperative, $\mathrm{N} \quad$ 2; and (c) He, $\mathrm{N} \quad$ 1, non-recuperative. Notation for the losses: $\dot{Q}_{0}$ are the optical losses in the heliostat field, $\dot{Q}_{l}$ are the heat losses in the receiver, $\dot{Q}_{i H S}$ are the losses in the heat transfer from the receiver to the working fluid of the turbine, $\dot{Q}_{C}$ are the losses in the combustion chamber, and $\dot{Q}_{i H C}$ are the losses in the heat exchanger associated to the combustion chamber.

heliostat has efficiencies below 0.35 . During winter there are more heliostats than in summer with high efficiencies (over 0.55) but at the same time there are a considerable amount of heliostats with poor efficiencies, between 0.20 and 0.25 . So, the distribution of efficiencies has shorter tails to worse efficiencies in summer than in winter. These points are plotted as a bar diagram in Fig. 14.

As it was aforementioned, the off-design analysis is carried out for 
$\mathrm{N}$
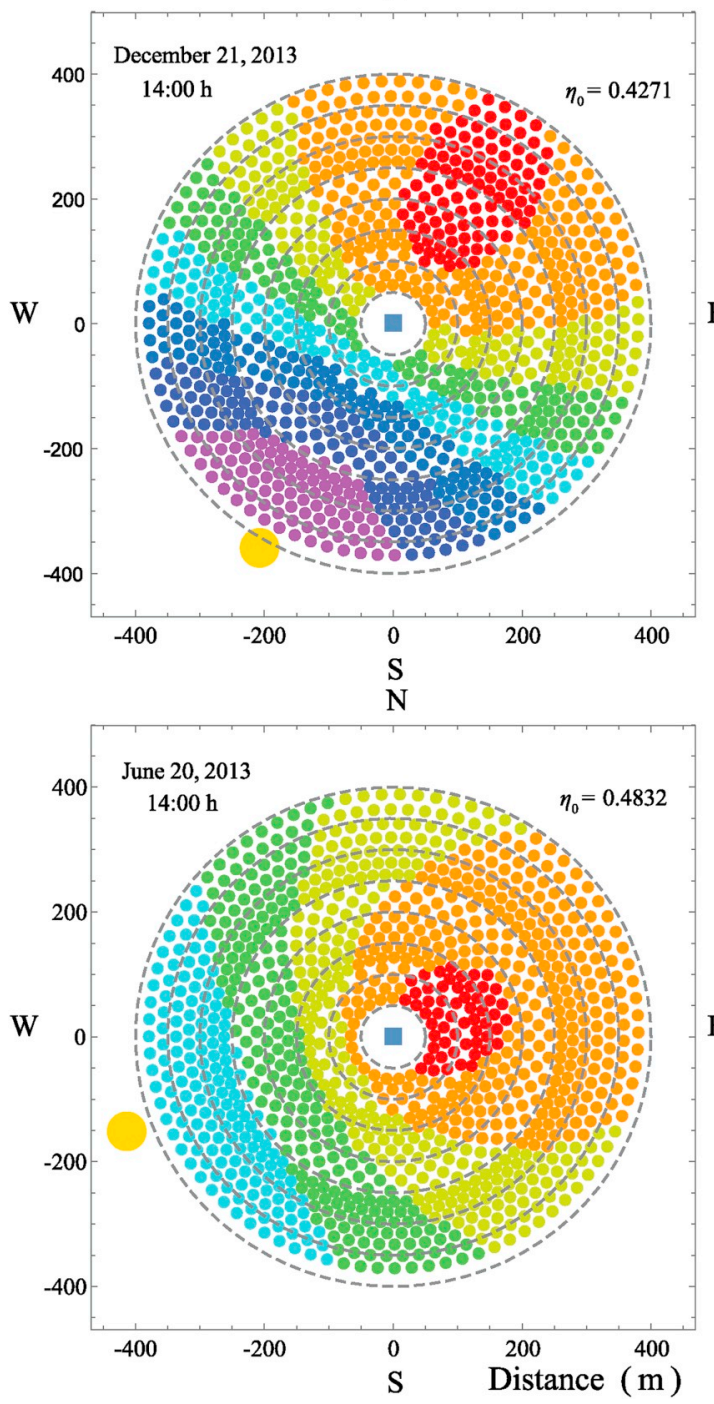

$\mathrm{N}$
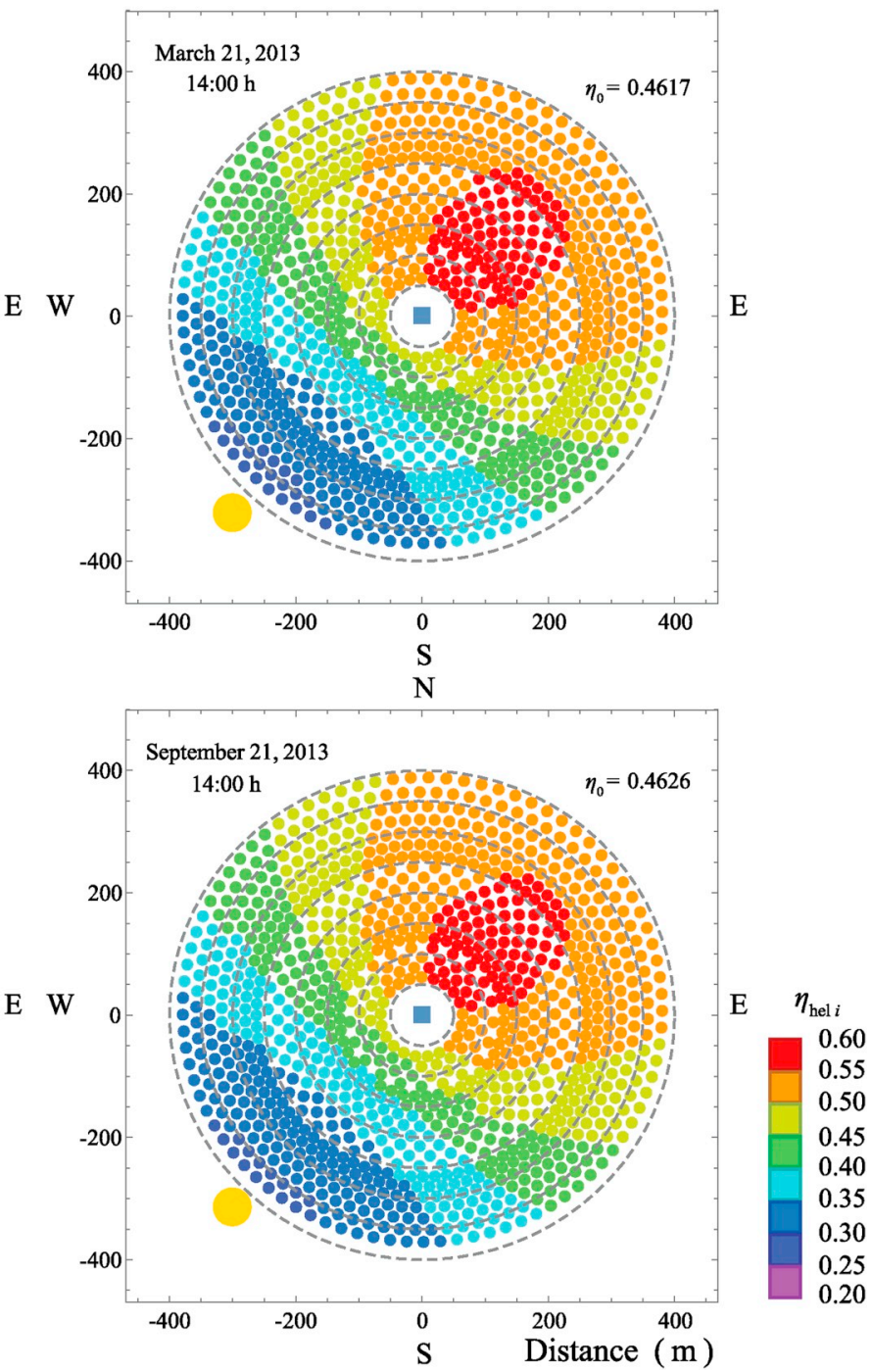

Fig. 13. Solar field efficiency plot for a representative day of each each season at the same hour.

three configurations: $\alpha$, dry air single non-recuperative case; $\beta$, dry air two compression and expansion stages recuperative layout; and $\gamma, \mathrm{He}$ single non-recuperative configuration. In this way, for the three selected optimum configurations, output records as efficiencies, fuel conversion rate, and solar share have been computed and represented throughout the four seasons (Figs. 15-17). Meteorological data employed in this simulation are taken from real measures not averaged nor smoothed [49] (see Fig. 3 in Ref. [34]).

These figures present some common features and different numerical scales depending on the particular plant configuration. Among the common characteristics the following are stressed. Solar subsystem efficiency, $\eta_{s}$, always reaches a maximum about $10 \mathrm{~h}$ (UTC) and then decreases slowly during the daytime. It is slightly below the optical efficiency, $\eta_{0}$, of the heliostat field because $\eta_{s}$ includes also the heat transfer losses in the receiver. The thermal efficiency of the heat engine, $\eta_{h}$, is approximately constant during any day and any hour, it only depends on the ambient temperature, because the turbine inlet temperature was considered as constant. Fuel conversion efficiency, $r_{e}$, increases during the daytime up to a maximum value about $14 \mathrm{~h}$ that corresponds with a decrease of the overall efficiency, $\eta$. During the daytime all subsystems are coupled and so, losses increase. During the night the solar subsystem is set off and all the losses come from the Brayton cycle. Solar share curves are widest and highest during summer but never reach $f \quad$ 1, i.e., for the dimensions of the heliostat field and receiver, the plant is always working on a hybrid mode. Maximum values as shown in Fig. 15, about 0.7, are reached for dry air in the case of a single stage non-recuperative configuration. On the other side, for He the solar share never goes up of about $20 \%$. As was mentioned before for the Sankey's schemes in Fig. 12 the largest values of overall efficiency are obtained in the case of He with a single stage non-recuperative configuration because the contribution of the solar subsystem is smaller.

With respect to the temperatures of the heat absorption process (see Figs. 18-20), it is remarkable that the inclusion of a recuperator increases the working temperature of the solar collector because the temperature of the fluid at the solar receiver inlet, $T_{x}$, is higher (about $900 \mathrm{~K}$, see Fig. 19). This fact makes that $T_{H S}$ increases above $1400 \mathrm{~K}$ in summer. Actually, in this case (dry air, recuperative, $N \quad 2$ ), the temperature of the solar collector, $T_{H S}$, can be above that of the combustion chamber, $T_{H C}$, because losses in the heat transfer from the solar subsystem to the fluid are larger. On the other side, solar receiver temperatures are below $1000 \mathrm{~K}$ for $\mathrm{He}, N \quad 1$, non-recuperative layout (see Fig. 20). In this case, the solar subsystem only increases the temperature of the working fluid from $T_{2}$ to $T_{x}$ ' about $100 \mathrm{~K}$.

Fig. 21 shows the natural gas consumption and the corresponding carbon dioxide emissions during a day for the three selected configurations and both for hybrid and non-hybrid (only combustion) modes for 

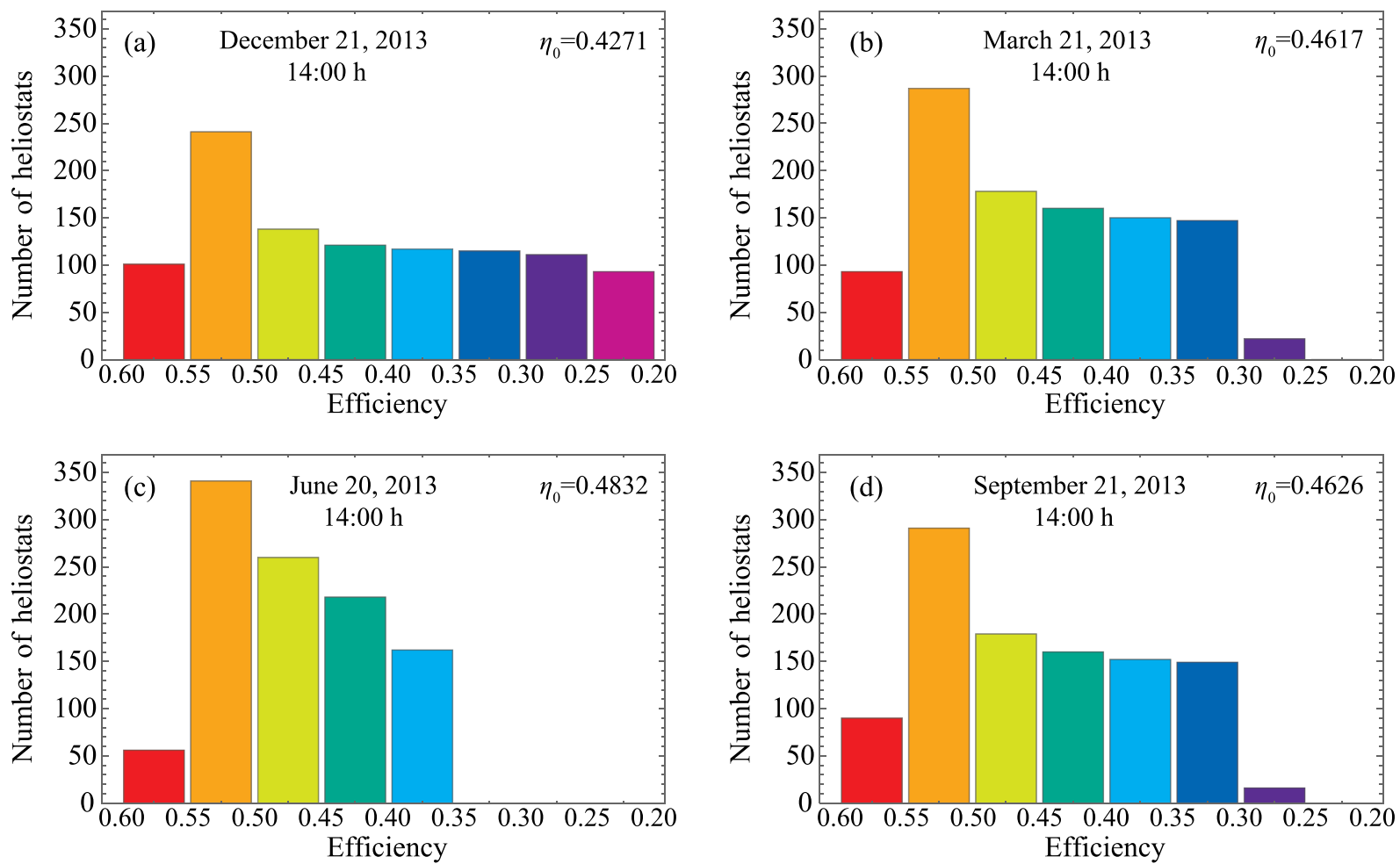

Fig. 14. Histogram corresponding to the number of heliostats with a given efficiency in the conditions of Fig. 13 .
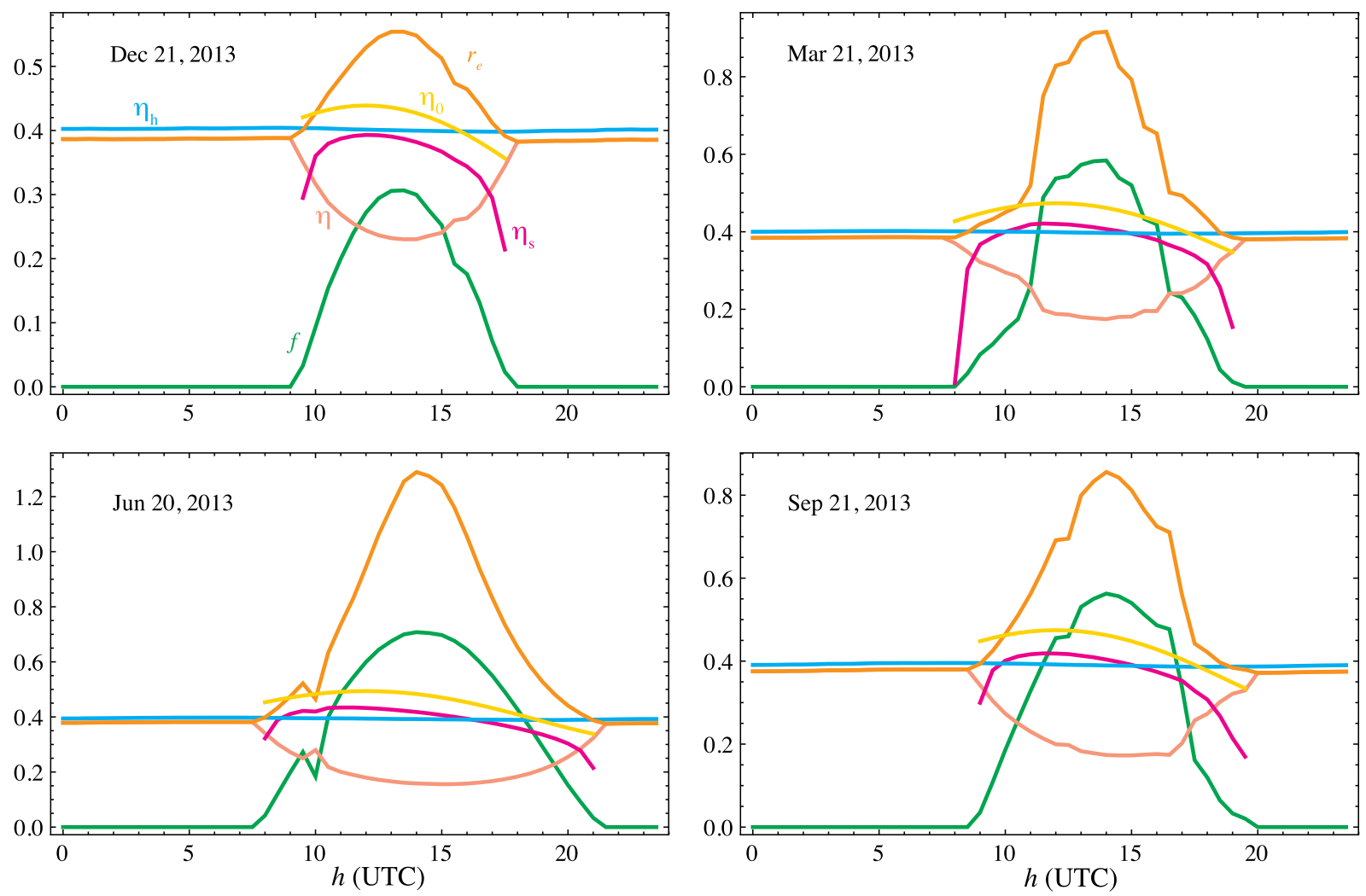

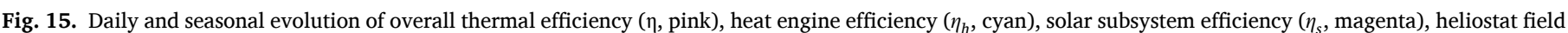

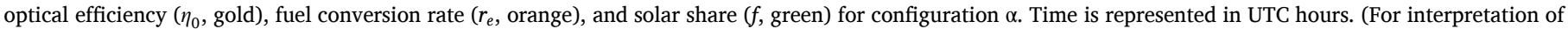
the references to colour in this figure legend, the reader is referred to the Web version of this article.) 

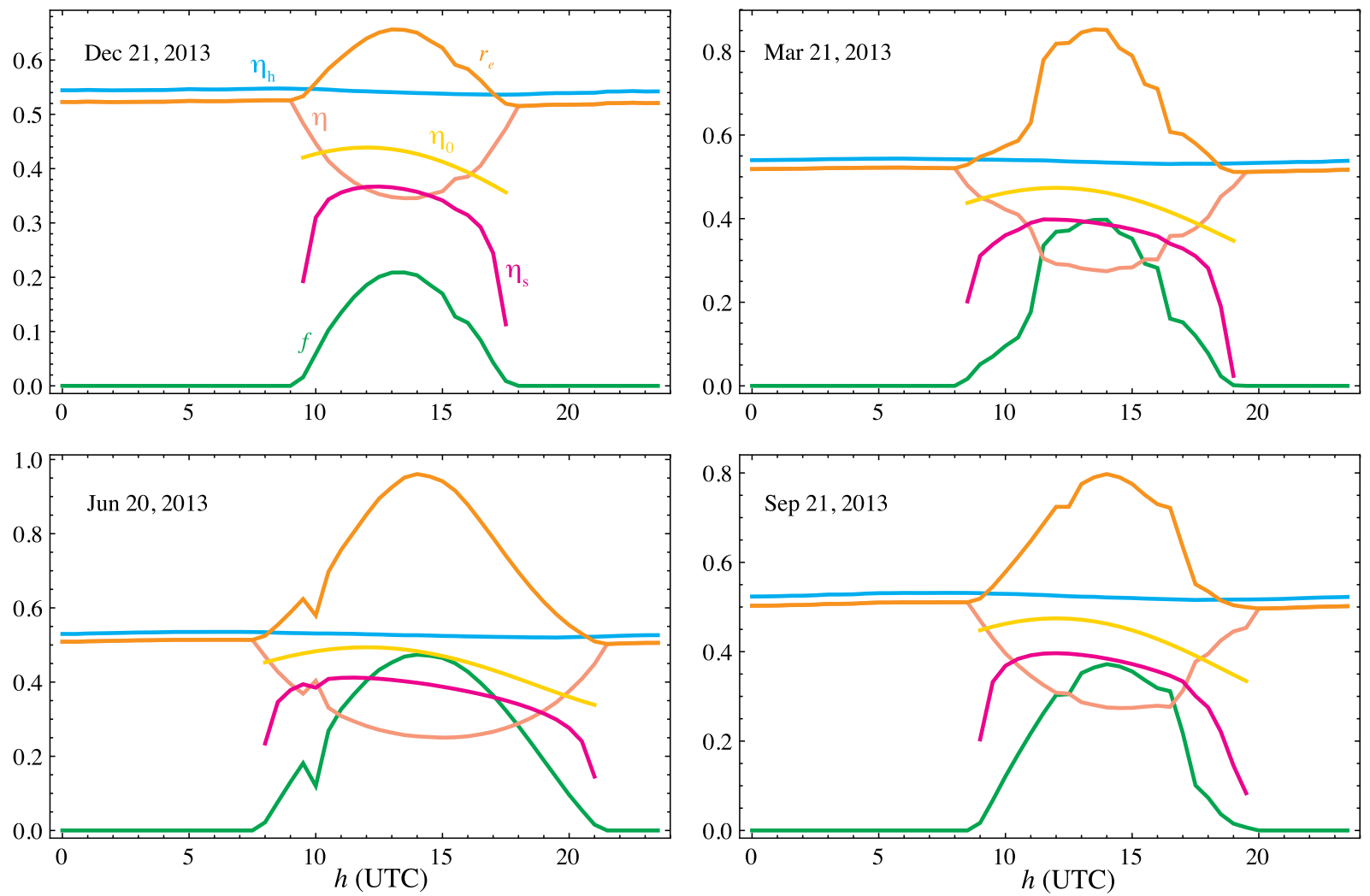

Fig. 16. Daily and seasonal evolution of solar share and efficiencies for configuration $\beta$. Notation as in Fig. 15 .
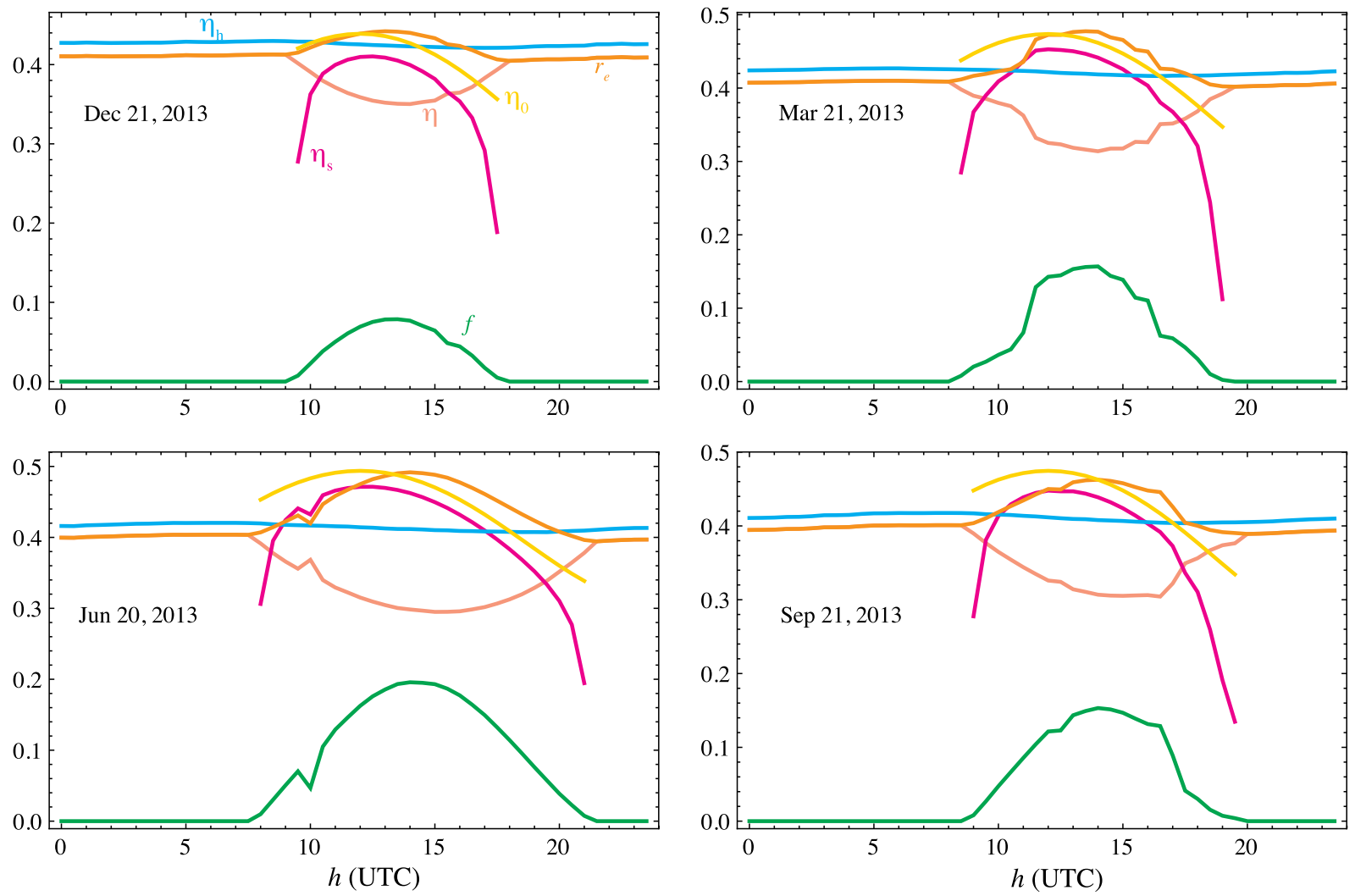

Fig. 17. Daily and seasonal evolution of solar share and efficiencies for configuration $\gamma$. Notation as in Fig. 15 . 

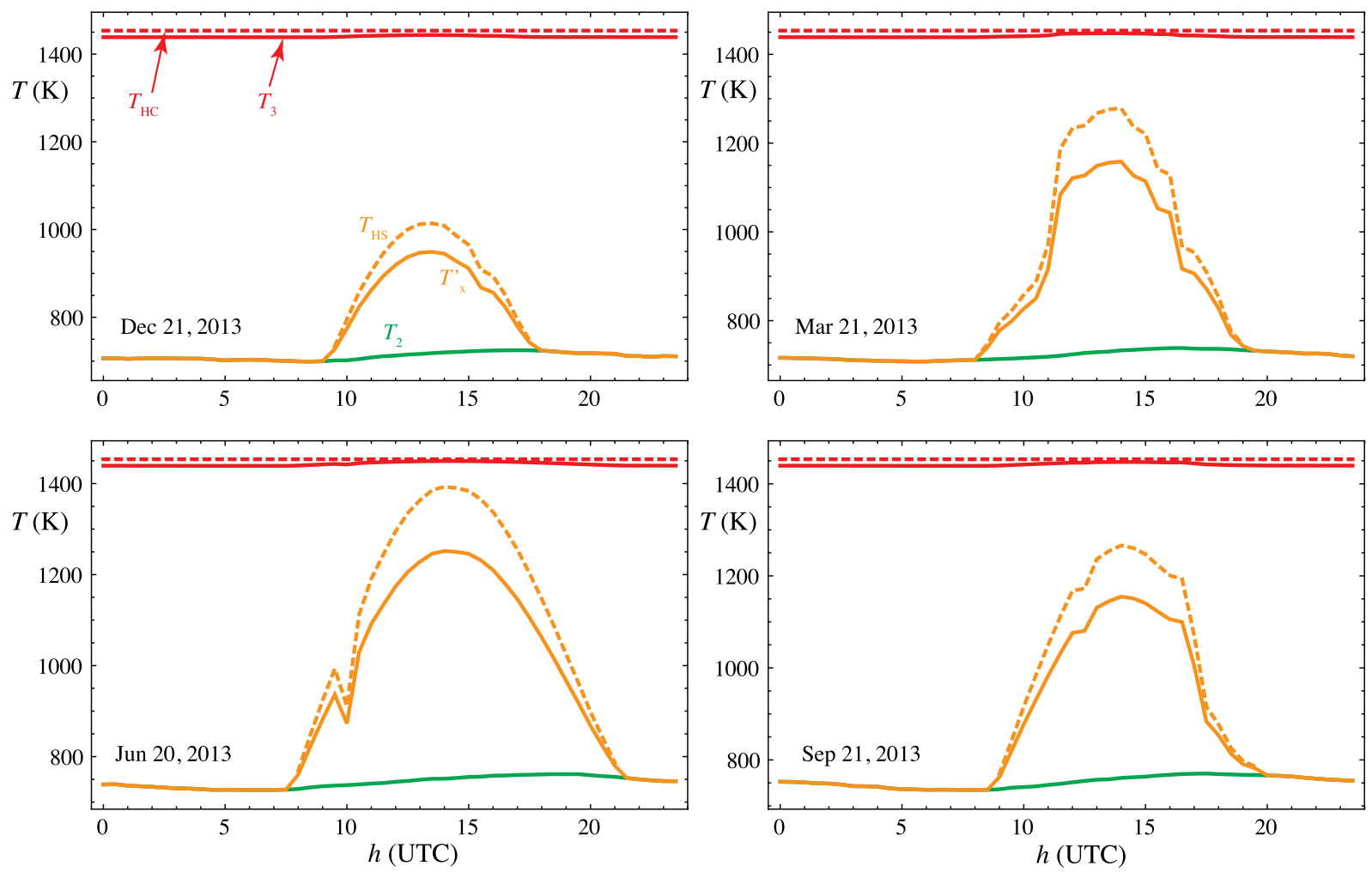

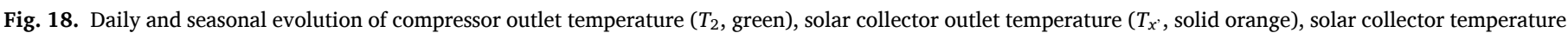

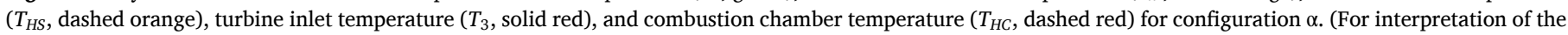
references to colour in this figure legend, the reader is referred to the Web version of this article.)
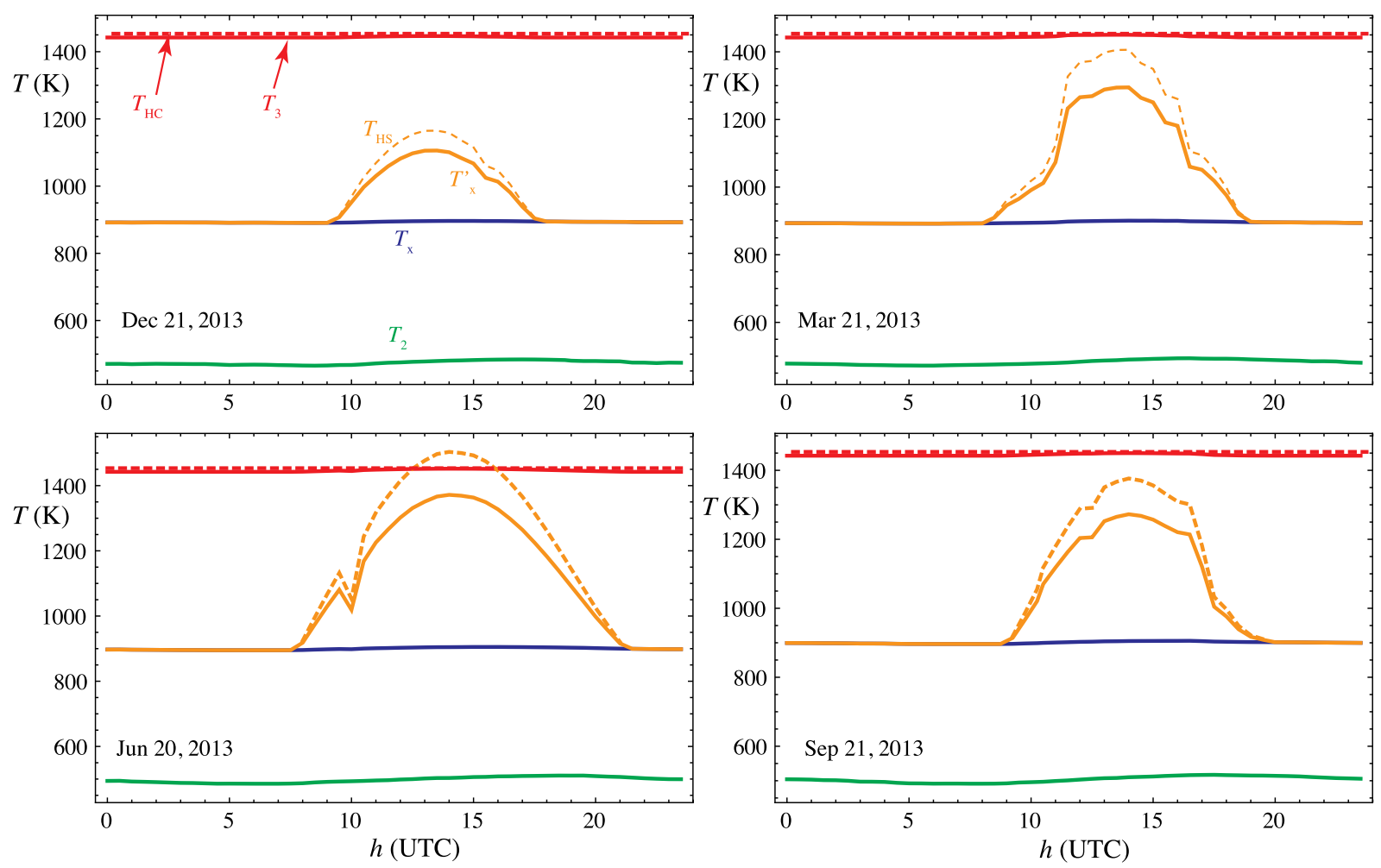

Fig. 19. Daily and seasonal evolution of temperatures for configuration $\beta$. Notation as in Fig. 18. 

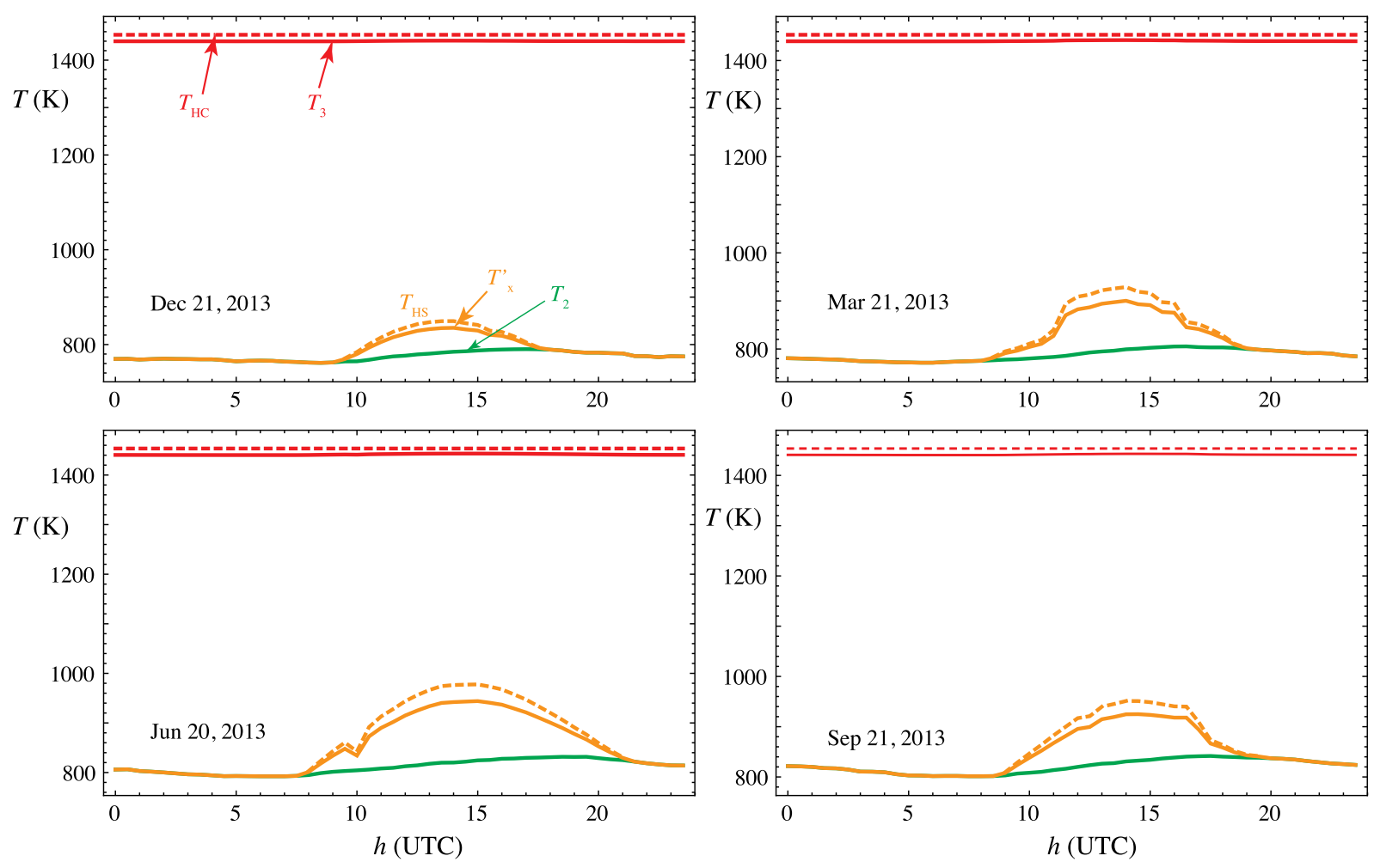

Fig. 20. Daily and seasonal evolution of temperatures for configuration $\gamma$. Notation as in Fig. 18.

comparing purposes. In the three configurations, it is clear that the difference between hybrid and non-hybrid mode is higher in summer, as a consequence of the associated higher irradiance and number of solar hours. In the case of He in single non-recuperative mode (Fig. 21(c)), differences between hybrid and non-hybrid configurations are smaller, in accordance with the lower solar share obtained before, which means that the solar contribution is relatively small. The better saving in fuel consumption and emissions is obtained for dry air, single stage, non recuperative configuration. It is about $22 \%$. For dry air, $N \quad 2$, recuperative case, the savings in summer are about $13 \%$ and for the case of $\mathrm{He}$, where the solar share is smaller, about $4 \%$. In winter, the maximum savings are got for $N \quad 1$, dry air, non-recuperative case and amount $4 \%$.

Finally, it should be stressed that all the results obtained in this section were computed with the optimum pressure ratio calculated at the design point in Sec. 4. At those conditions solar irradiance was taken as $G \quad 760 \mathrm{~W} / \mathrm{m}_{2}$ (Table 4). The optimization process was repeated for several other values of $G$ and approximately the same values of the optimum pressure ratios were found. So, all the results presented in this section can be considered as independent of the particular values of the pressure ratios chosen for the plant configurations considered. In other words, it was checked that the decision about the optimum pressure ratio regarding global efficiency is consistent throughout any day and any season.

\section{Conclusions}

In which refers to pre-design conditions, this work shows that a key point is to design the system as a whole, including ingredients from the solar field (dimensions and efficiency), the solar receiver (size and temperature level), and the gas turbine (working fluid, pressure ratio, recuperation and number of compression/expansion stages). Particularly, curves of all subsystems efficiencies as functions of the Brayton cycle pressure ratio were presented for four working fluids (dry air, nitrogen, carbon dioxide, and helium) at subcritical conditions (except for
He where the cycle could be transcritical). Nitrogen and air lead to similar overall efficiencies and optimum pressure ratios although slightly better records are obtained for nitrogen. Helium causes very high power output and efficiencies (provided that the same working fluid mass rate is considered for all fluids for the sake of comparison). Subcritical $\mathrm{CO}_{2}$ leads to a similar thermal overall efficiency that dry air but shows better fuel conversion efficiencies (at higher pressure ratios).

In all cases a substantial increase in overall efficiency is predicted when a single-stage plant configuration is substituted by a twocompressions two-expansions cycle (with a subsequent increase in fuel consumption). For larger number of compression/expansion stages, improvement is not so significant. The role played by a recuperator located in between the last turbine and the solar subsystem is also crucial. On one side, the recuperator increases overall efficiency (specially at low pressure ratios, although it depends on the peculiarities of the working fluid), but on the other it increases the temperature level of the solar receiver and so, the requirements for the materials. For all the fluids checked, solar receiver temperature decreases with higher pressure ratios for recuperative configurations and have the opposite behavior for single-stage non-recuperative layouts. In most configurations, temperatures are well above $1000 \mathrm{~K}$, except single-stage configurations for He. It is noticeable that single-stage configurations for $\mathrm{CO}_{2}$ lead to temperatures quite below those for air or nitrogen.

Numerical evaluation of losses in each plant subsystem was presented in detail. In relative terms, optical losses in the heliostat field seem to be the main bottleneck for the whole system. Thus, those configurations with larger solar share provoke worse values of overall plant thermal efficiency (but probably better values of the fuel conversion efficiency). Sankey's diagrams for losses show that there is a wide margin to set plant design for a particular solar field (by considering different working fluids, pressure ratios, number of compression/ expansion stages, recuperation, etc.).

Daily and seasonal analysis have been reported for several selected plant configurations in hourly terms. For instance, dry air working on a single-stage non-recuperated cycle solar share is about 0.7 and allows 

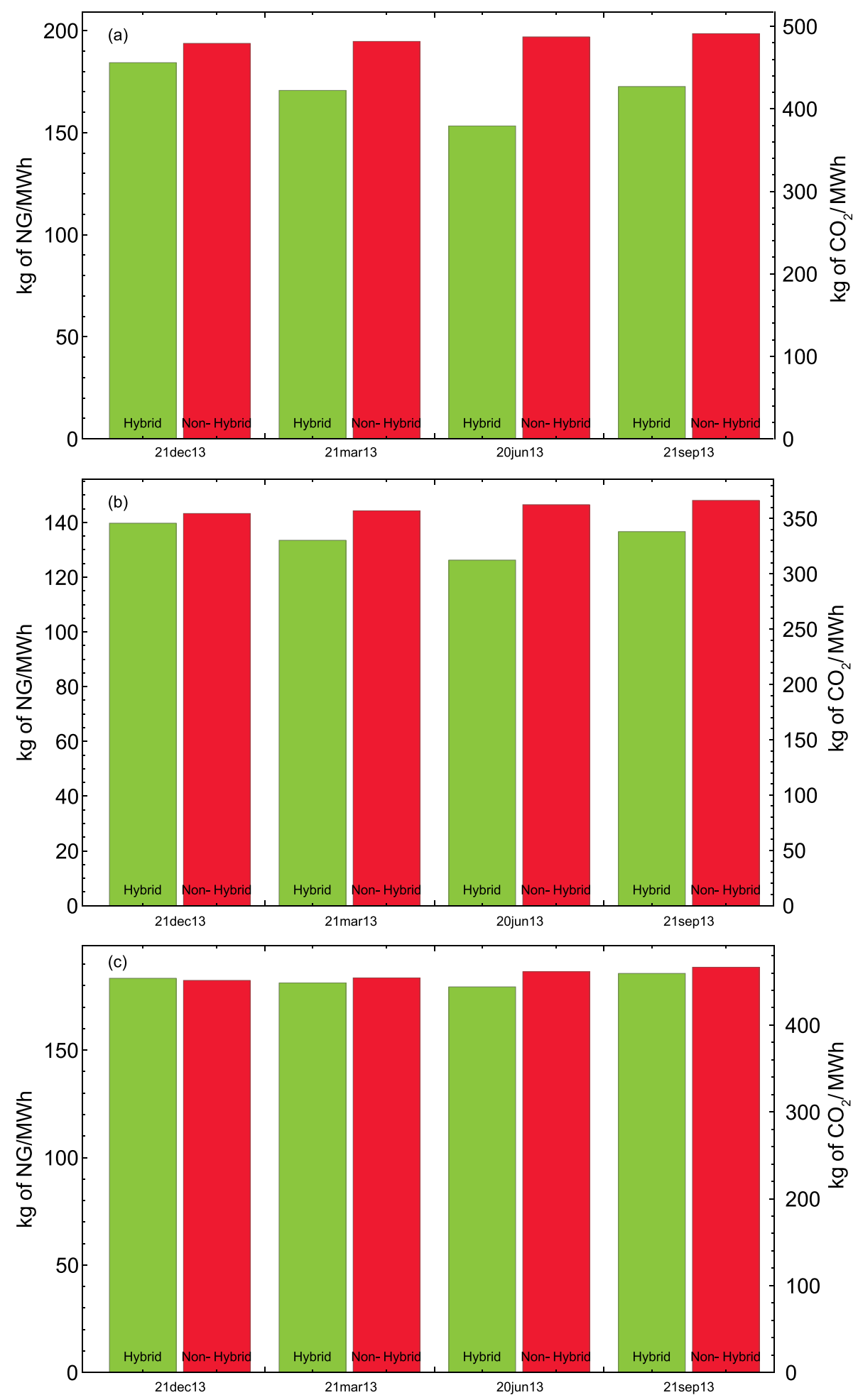

Fig. 21. Natural gas consumption (left axis) and carbon dioxide emissions (right) for the four different seasons and in both hybrid and non-hybrid configurations. (a) Configuration $\alpha$; (b) configuration $\beta$; and (c) configuration $\gamma$.

fuel savings (with respect to a plant operating in a pure combustion mode with natural gas) and $\mathrm{CO}_{2}$ emissions over $20 \%$ in summer and about $10 \%$ in winter (with solar shares about 0.3 ). Higher overall efficiencies (about 1.5 times larger) are obtained for dry air in a twocompression two-expansion stages with recuperation. In this case, a solar share of 0.45 in summer is predicted (in similar conditions) with a fuel saving about $13 \%$ with respect to non-hybrid operation. Finally, for helium in a single-stage non-recuperative cycle, solar share decreases to
0.2 , solar receiver temperatures are considerable lower, efficiencies can reach values about 0.34 , but fuel saving is poorer, about $4 \%$ in summer.

\section{Summary and future work}

A comprehensive model for CSP central tower power plants developing a hybrid Brayton cycle has been presented. The ultimate plant objective is to efficiently produce clean electricity at a scale of about 
$20 \mathrm{MW}$ without intermittencies, with a reduced water consumption and with not too high investment costs. The model incorporates detailed solar field efficiency calculations and a simplified model for heat transfer losses at the tubular receiver. It also includes a flexible and realistic thermodynamic model for the gas turbine with all the main losses sources existing in real power blocks. So, the model for the overall plant encompasses rational, but at the same time comprehensive, submodels for the main plant subsystems. In this way efficiencies, solar share, power output, and other records can be obtained as combinations of the corresponding records for the plant subsystems. This approach allows, apart from obtaining realistic predictions for plant output parameters, to perform pre-design optimization studies considering the plant as a whole. And so, to propose overall plant configurations, to locate efficiency bottlenecks, and to propose optimum intervals for selected design parameters. Particularly in this work, different working fluids for the Brayton cycle developed by the gas turbine were analyzed, as well as single- or multi-stage compression and expansion plant layouts. The relevance of a recuperator in which respect to overall plant efficiency and temperatures at the solar receiver was also explored. Moreover, the model allows for numerical computations at off-design conditions for whichever plant location and seasonal or meteorological conditions. So, hourly curves can be obtained for any parameter and the influence of plant design estimated in close to reality conditions.

As reference values to size the installation, GEMASOLAR plant dimensions were adopted [50]. This commercial plant, located at the south of Spain is based on a different concept, vapor turbine with molten salt storage, but one of the objectives of this work was to analyze the possibilities of a similar size plant working on a hybrid Brayton cycle without storage. Several subcritical and transcritical working fluids for the Brayton cycle were considered. The following conclusions were extracted:
Numerical overall efficiencies obtained for air and nitrogen are similar, as well as the optimum pressure ratios. Maximum efficiencies are slightly above for nitrogen.

Subcritical carbon dioxide gives similar overall efficiencies but better solar share and fuel conversion efficiencies than air or nitrogen.

Transcritical helium provokes very good overall efficiencies but lower solar share because achieved solar collector temperatures are below those for the other fluids.

For all fluids collector temperatures for the optimized configurations are in the interval $925,1420 \mathrm{~K}$.

Analyses, as the one developed here, suggest as possible lines for future research at least the following: to improve solar field design as a main restriction to enhance overall plant output records, to increase the temperature limits associated to the materials and the design of the solar receiver because most plant configurations require temperatures around or above $1000 \mathrm{~K}$, to explore (simultaneously) thermodynamic plant configurations capable to produce good efficiencies at reduced maximum temperatures, and to analyze and experience the behavior of the turbomachinery (compressors and turbines) and heat exchangers with different working fluids in wide temperature and pressure intervals. The achievement of at least some of these objectives could allow to suggest plant designs and materials that make this plant concept interesting from the commercial viewpoint to companies specialized in the production of clean energy.

\section{Acknowledgements}

Financial support from University of Salamanca and Junta de Castilla y Leon (project SA017P17) is acknowledged. R.P. Merchan also acknowledges a pre-doctoral grant by Banco de Santander of Spain.

\section{Appendix A. Brayton cycle model details}

Next, the cycle stages developed by the working fluid, considered as an ideal gas with mass flow rate is $\dot{m}$ and with temperature dependent specific heat, $c_{w} T$, are summarized:

1. In the first stage, the working fluid is compressed by means of $N_{c}$ compressors, with an isentropic efficiency $\varepsilon_{c} \quad T_{2 s} \quad T_{1} / T_{2} \quad T_{1}$, being $T_{1}$ the temperature at which the working fluids enters the first compressor, $T_{2}$, the exit temperature of the last compressor and $T_{2 s}$, the hypothetical temperature after compressions if they were isentropic. It is assumed that the $T_{1}$ temperature is the same for all compressors because an intercooler is placed in between each pair of them.

2. The second stage corresponds to the heat absorption process, divided into three substages. The working fluid temperature is first increased up to $T_{x}$ by means of a recuperator with efficiency $\varepsilon_{r} \quad T_{x} \quad T_{2} / T_{4} \quad T_{2}$, where $T_{4}$ refers to the temperature after the expansion process. Then, the solar heat is provided, rising the temperature up to $T_{x}$. And, finally, heat from the main combustion chamber is absorbed by the working fluid, reaching the temperature $T_{3}$. The global pressure decay in the total heat absorption process is quantified by the parameter $\rho_{H} \quad p_{\mathrm{H}} \quad \Delta p_{\mathrm{H}} / p_{\mathrm{H}}$, even though each heat absorption substage has its own pressure losses. This parameter is a measure of the whole pressure decay in the heat input process. $p_{\mathrm{H}}$ is the highest pressure and $p_{\mathrm{H}} \quad \Delta p_{\mathrm{H}}$, the first turbine inlet pressure.

3. The working fluid expansion takes place in the third stage through $N_{t}$ turbines that have an associated isentropic efficiency, $\varepsilon_{t} \quad T_{4} \quad T_{3} / T_{4 s}$ $T_{3} . T_{4 s}$ corresponds to the temperature after the expansion processes if they were isentropic. An intermediate reheater is needed between each pair of turbines for reaching the same inlet temperature, $T_{3}$, in all cases.

4. In the last stage, the working fluid releases the excess heat in two processes. First, by means of the recuperator, which decreases the temperature to $T_{y}$. And, then, with the help of a heat exchanger connected to the ambient, whose effectiveness is $\varepsilon_{\mathrm{L}} T_{1} T_{y} / T_{L} T_{y}$, recovering in this way the initial conditions of the cycle. $T_{L}$ refers to the ambient temperature. In the same way as in the heat absorption process, for the heat release process, a global pressure loss parameter can be defined: $\rho_{\mathrm{L}} \quad p_{\mathrm{L}} \quad \Delta p_{\mathrm{L}} / p_{\mathrm{L}}$, where $p_{\mathrm{L}}$ is the pressure at the exit of the expansion processes and $p_{\mathrm{L}}$ $\Delta p_{\mathrm{L}}$ is the lowest pressure.

The global pressure ratio of the whole cycle is defined as: $r_{p} \quad p_{\mathrm{H}} / p_{\mathrm{L}} \quad \Delta p_{\mathrm{L}}$. One of the advantages of this model is that analytical expressions for the main cycle records can be obtained: all the temperatures involved in the cycle can be expressed in terms of a set of parameters associated with the cycle size and geometry and with the thermal irreversibilities, as our group shown in Ref. [34]. For $T_{2}$ and $T_{4}$, it is possible to obtain:

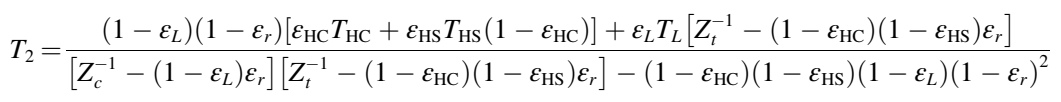


$T_{4}$\begin{tabular}{ccccccccccccccccc}
$\varepsilon_{\mathrm{HC}} T_{\mathrm{HC}}$ & $\varepsilon_{\mathrm{HS}} T_{\mathrm{HS}} 1$ & $\varepsilon_{\mathrm{HC}}$ & $Z_{c}{ }^{1}$ & 1 & $\varepsilon_{L}$ & $\varepsilon_{r}$ & $\varepsilon_{L} T_{L}$ & 1 & $\varepsilon_{\mathrm{HC}}$ & 1 & $\varepsilon_{\mathrm{HS}}$ & 1 & $\varepsilon_{r}$ \\
\hline$Z_{c}{ }^{1} 1$ & $\varepsilon_{L}$ & $\varepsilon_{r}$ & $Z_{t}{ }^{1}$ & 1 & $\varepsilon_{\mathrm{HC}}$ & 1 & $\varepsilon_{\mathrm{HS}}$ & $\varepsilon_{r}$ & 1 & $\varepsilon_{\mathrm{HC}}$ & 1 & $\varepsilon_{\mathrm{HS}}$ & 1 & $\varepsilon_{L}$ & 1 & $\varepsilon_{r}{ }^{2}$
\end{tabular}

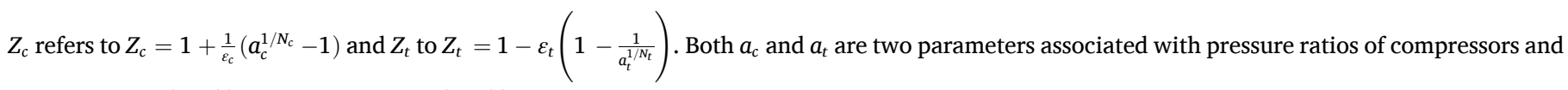

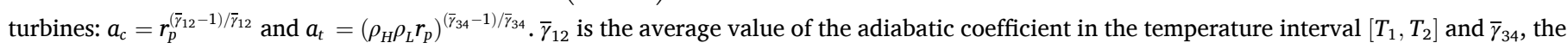
same but in the temperature interval $T_{3}, T_{4}$.

\section{Appendix B. Numerical data and validation}

The main differences between GEMASOLAR plant and our model are summarized in Table 3. Regarding the power conversion system, our model employs a Brayton cycle instead of the Rankine used by GEMASOLAR because one of the objectives of this work is to compare both technologies in a similar size plant. Gas turbines consume less water than steam ones that is an additional advantage in regions with good solar conditions and (usually) scarce water resources. They are also efficient, reliable and flexible since thermal inertia is not too high [51].

Moreover, our model describes a system which gets the constant power by means of a combustion chamber rather than the molten salt storage system, that allows GEMASOLAR to produce energy up to $15 \mathrm{~h}$ without solar radiation [18]. This scheme is chosen because of its direct integration in gas turbine plants and because allows a very flexible plant operation avoiding an elevated number of heliostats.

As it has been already mentioned, the gas turbine has been chosen looking for a commercial turbine with a power output similar to the one of GEMASOLAR, so the difference between both of them is about $1 \mathrm{MW}$. Finally, with this model, the total number of heliostats is an output parameter, not an input one as it is usual. This happens because the number of rows is elected and the maximum number of heliostats that fit in each row are placed in the field (taking into account all the considerations in Sec. 2.2). Then, the rows number is chosen by taking into account a Thermoflex ${ }^{\circledR}$ simulation performed for the overall model validation. In addition, although GEMASOLAR employs 2650 heliostats, in our simulation 1037 heliostats are considered. A higher number of heliostats results in too much high solar collector temperatures that the materials cannot withstand.

Table 3

Main differences between GEMASOLAR plant and our model.

\begin{tabular}{lll}
\hline & Our model & Gemasolar \\
\hline Thermodynamic cycle & Brayton (gas turbine) & Rankine (steam turbine) \\
Constant power & Hybridization & Molten salt storage \\
means & (combustion chamber) & small combustion chamber \\
Power output & 20.91 MW & 19.9 MW \\
Heliostats number & 1037 (19 rows) & 2650 \\
\hline
\end{tabular}

Next the main parameters set to run the model previously developed and its validation are detailed. Meteorological data (direct solar irradiance, $G$, ambient temperature, $T_{L}$, and ambient pressure, $p_{L}$ ) are taken from Meteosevilla [49] and gathered in Table 4. June 20, 2013, at 12:00 $\mathrm{h}$ is chosen as the design point time. However, regarding the off-design analysis, four days representing the four seasons are selected [34] and all the calculations are carried out every half an hour throughout each day. The location considered for the plant is the same as GEMASOLAR, Fuentes de Andalucía (Seville, Spain) [50].

Table 4

Meteorological, date and location data at the design point for the on-design simulation.

\begin{tabular}{ll}
\hline & Date and location \\
\hline$\varphi$ & $37^{\circ} 33^{\prime} 29.11^{\prime \prime} N$ (Fuentes de Andalucía, Seville) \\
Day of the year & 171 \\
Time $(h)$ & 12 \\
Meteorological data[49] & \\
$T_{L} K$ & 296.55 \\
$p_{L}$ bar & 1.00439 \\
$G \quad W / m^{2}$ & 760 \\
\hline
\end{tabular}

Heliostat field and solar receiver

Table 5

Table of parameters values employed in the Mathematica ${ }^{\circledR}$ simulation (GEMASOLAR plant [41]).

\begin{tabular}{lll}
\hline Parameter & Symbol & Value \\
\hline Height of the tower supporting the receiver & $T H T$ & $130 \mathrm{~m}$ \\
Height of the receiver & $L R$ & $10.5 \mathrm{~m}$ \\
Diameter of the receiver & $D R$ & $8.4 \mathrm{~m}$ \\
Height of each heliostat & $L H$ & $10.95 \mathrm{~m}$ \\
Width-height ratio of each heliostat & $w_{r}$ & 1.0 \\
Focusing & & \\
\end{tabular}

(continued on next page) 
Table 5 (continued)

\begin{tabular}{lll}
\hline Parameter & Symbol & Value \\
\hline Separation distance between adjacent heliostats & $d_{s}$ & $3.285 \mathrm{~m}$ \\
Minimum radius of the heliostat field & $R_{\min }$ & $65 \mathrm{~m}$ \\
Standard deviation due to Sun shape & $\sigma_{S u n}$ & $2.51 \mathrm{mrad}$ \\
& & \\
Blocking and shadowing & $f_{b} \cdot f_{s}$ & 0.95 \\
Actual mirror reflectivity & $\rho$ & 0.836 \\
\hline
\end{tabular}

Main parameters associated to the solar subsystem are gathered in Table 5 . A tubular receiver of $10.5 \mathrm{~m}$ height and diameter $8.4 \mathrm{~m}$ is placed at the top of a $140 \mathrm{~m}$ height tower. Every heliostat is assumed as square $\left(\begin{array}{ll}w_{r} & 1\end{array}\right)$, with $10.95 \mathrm{~m}$ of side. In this way, the heliostat area is approximately 120 $\mathrm{m}_{2}$, the same as in GEMASOLAR [50]. With respect to the heliostats distribution, a separation distance between adjacent heliostats of $3.285 \mathrm{~m}$ is considered [36]. The diameter of the field is about $800 \mathrm{~m}$. The minimum distance from the tower to the first heliostats row is taken as $65 \mathrm{~m}$ [36]. The standard deviation due to Sun shape is assumed $2.51 \mathrm{mrad}$, as in [36].

Regarding the optical efficiency of the heliostat field, the blocking factor and the shadowing factors are taken together and constant in such a way that $f_{b} . f_{s h} \quad 0.95$ as other authors use to do $[36,37,40]$. Also, the actual mirror reflectivity, $\rho \quad 0.836$, is the same for all the heliostats and it is the product of the nominal reflectivity $\left(\rho_{n} \quad 0.88\right)$ by the nominal cleanliness $\left(C_{n} \quad 0.95\right)$ [41].

A cylindrical receiver of height $10.5 \mathrm{~m}$ and of diameter $8.4 \mathrm{~m}$ is located at the top of the $150 \mathrm{~m}$ height tower. A simple focusing is supposed for simplicity, but the model can work also with double and triple focusing.

\section{Power block validation}

For the turbine choice and validation, the Thermoflex ${ }^{\circledR}$ database [52] has been employed. This database presents detailed information about different commercial gas turbines. The decision of the particular turbine has been done looking for a commercial turbine with a power output similar to the one of GEMASOLAR [18] (19.9 MW), an adequate turbine inlet temperature, and a good thermal efficiency. In this way, the Solar Titan 250-30000S gas turbine (Caterpillar) [53] was chosen. For the compressor, the Solar C85 gas compressor [53] was elected because it has the largest isentropic efficiency (above $89 \%$ ) from among the compatible compressors with the Solar Titan 250 gas turbine.

Turbine validation data are gathered in Table 6 . The first block are input data. For numerical computations, the working fluid mass flow, $\dot{m}$, and the overall pressure ratio, $r_{p}$, values are taken from Thermoflex ${ }^{\circledR}$ database [52]. The isentropic efficiencies of the turbine and compressor, $\varepsilon_{t}$ and $\varepsilon_{c}$, are collected from Caterpillar ${ }^{\circledR}$ [53]. Pressure losses were assumed similar in the heat input and heat release, $9.4 \%$ in relative terms. The effectiveness of the recuperator was taken as 0.775 .

The other parameters in Table 6 are output records obtained from the Brayton cycle model in Sec. 2.4. For the power output, our model predicts $20.91 \mathrm{MW}$, which means a deviation of $\quad 0.89 \%$ with respect to the Thermoflex ${ }^{\circledR}$ database. The predicted thermal efficiency deviates $2.37 \%$ and the turbine outlet temperature, $2.95 \%$, which is the highest deviation. On the other hand, the smallest deviation corresponds to turbine inlet temperature, about $0.04 \%$.

Then, it can be concluded that the thermodynamic model of the turbine agrees very well with Thermoflex® data. It is important to note that this validation has been carried out for the mono-stage configuration and for dry air as working fluid.

Table 6

Parameters and output records values for Thermoflex ${ }^{\circledR}$ data and for the Mathematica ${ }^{\circledR}$ simulation in the turbine validation. (*) This parameter was taken directly from Caterpillar information [53].

\begin{tabular}{|c|c|c|c|}
\hline Variable & $\begin{array}{l}\text { Thermoflex }{ }^{\circledR} \\
\text { data }\end{array}$ & $\begin{array}{l}\text { Mathematica }{ }^{\circledR} \\
\text { simulation } \\
\text { (our model) }\end{array}$ & $\begin{array}{l}\text { Relative } \\
\text { deviation } \\
(\%)\end{array}$ \\
\hline \multicolumn{4}{|l|}{ Input } \\
\hline $\begin{array}{l}\text { Working fluid mass flow } \\
\qquad(\dot{m}, \mathrm{~kg} / \mathrm{s})\end{array}$ & 67 & 67 & \\
\hline $\begin{array}{l}\text { Overall pressure ratio } \\
\qquad\left(r_{p}\right)\end{array}$ & 23.4 & 23.4 & \\
\hline $\begin{array}{l}\text { Compressor isentropic efficiency } \\
\left(\varepsilon_{t}\right)\end{array}$ & $>0.89$ & 0.895 & \\
\hline \multicolumn{4}{|l|}{ Output } \\
\hline $\begin{array}{l}\text { Power output } \\
\qquad(P, M W)\end{array}$ & 21.20 & 20.91 & 0.89 \\
\hline $\begin{array}{l}\text { Heat Rate } \\
\qquad(H R, k J / k W h)\end{array}$ & 9256 & 9041 & 2.33 \\
\hline $\begin{array}{l}\text { Thermal efficiency } \\
\qquad\left(\eta_{h}\right)\end{array}$ & 0.389 & 0.398 & 2.37 \\
\hline $\begin{array}{l}\text { Turbine inlet temperature } \\
\qquad\left(T_{3}, K\right)\end{array}$ & 1450 & 1451 & 0.04 \\
\hline $\begin{array}{l}\text { Turbine outlet temperature } \\
\qquad\left(T_{4}, K\right)\end{array}$ & 736 & 758 & 2.95 \\
\hline
\end{tabular}

\section{References}

[1] Dunham M, Iverson B. High-efficiency thermodynamic power cycles for concentrated solar power systems. Renew Sustain Energy Rev 2014;30:758-70.
[2] Nathan GJ, Jafarian M, Dally BB, Saw WL, Ashman PJ, Hu E, Steinfeld A. Solar thermal hybrids for combustion power plant: a growing opportunity, Prog. Ener. Comb. Sci. 2018;64:4-28.

[3] Weinstein L, Loomis J, Bhatia B, Bierman D, Wang E, Chen G. Concentrating solar power. Chem Rev 2015;115:12797-838. 
[4] Islam MT, Huda N, Abdullah AB, Saidur R. A comprehensive review of state-of-theart concentrating solar power (CSP) technologies: current status and research trends. Renew. Sust. Energy Rev 2018;91:987-1018.

[5] Jamel M, Abd Rahman A, Shamsuddin A. Advances in the integration of solar thermal energy with conventional and non-conventional power plants. Rene. Sust. Energ. Rev. 2013;20:71-81.

[6] Jelley N, Smith T. Concentrated solar power: recent developments and future challenges. J. Power and Energy 2015;229:693-713.

[7] Collado FJ, Turegano JA. Calculation of the annual thermal energy supplied by a defined heliostat field. Sol Energy 1989;42:149-65.

[8] Noone C, Torrilhon M, Mitsos A. Heliostat field optimization: a new computationally efficient model and biomimetic layout. Sol Energy 2012;86: 792-803.

[9] Wendelin T. SolTRACE: a new optical modeling tool for concentrating solar optics, Tech. rep., National Renewable Energy Laboratory (NREL). 2003.

[10] Schmitz M, Schwarzbozl P, Buck R, Pitz-Paal R. Assessment of the potential improvement due to multiple apertures in central receiver systems with secondary concentrators. Sol Energy 2006;80:111-20. https://doi.org/10.1016/j. solener.2005.02.012.

[11] Collado FJ, Guallar J. Campo: generation of regular heliostat fields. Renew Energy 2012;46:49-59.

[12] Carrizosa E, Domínguez-Bravo C, Fernandez-Cara E, Quero M. A heuristic method for simultaneous tower and pattern-free field optimization on solar power systems. Comput Oper Res 2015;57:109-22.

[13] Avila-Marín A. Volumetric receivers in solar thermal power plants with centra receiver system technology: a review. Sol Energy 2011;85:891-910.

[14] Lopez-Herraiz M, Bello Fernandez A, Martinez N, Gallas M. Effect of the optical properties of the coating of a concentrated solar power central receiver on its thermal efficiency. Sol. Energ. Mat. \& Sol. Cells 2017;159:66-72.

[15] Uhlig R, Flesch R, Gobereit B, Giuliano S, Liedke P. Strategies enhancing the efficiency of cavity receivers. Energ. Proc. 2014;49:538-50.

[16] del Río A, Korzynietz R, Brioso JA, Gallas M, Ordoñez I, Quero M, Díaz C. Soltrec pressurized volumetric solar air receiver technology. Energ. Proc. 2015;69:360-8.

[17] Ho CK, Iverson BD. Review of high-temperature central receiver designs for concentrating solar power. Renew Sustain Energy Rev 2014;29:835-46.

[18] Burgaleta S, Ramírez DJI. Gemasolar, the first tower thermosolar commercial plant with molten salt storage. In: Proceedings of SolarPACES; 2011. Granada, Spain.

[19] [link], https://www.solarreserve.com/en/global-projects/csp/crescent-dunes.

[20] [link], https://ec.europa.eu/europeaid/blending/noor-iii-tower-plant-ouarzazatesolar-complex en.

[21] Behar O, Khellaf A, Mohammedi K. A review of studies on central receiver solar thermal power plants. Renew. Sust. Energy Rev 2013;23:12-39.

[22] Okoroigwe E, Madhlopa A. An integrated combined cycle system driven by a solar tower: a review. Renew Sustain Energy Rev 2016;57:337-50.

[23] Tech. rep. Solar hybrid gas turbine electric power system (SOLGATE). European Comission; 2005.

[24] Tech. rep. Solar-hybrid power and cogeneration plants. European Commission; 2011. URL ordis.europa.eu/publication/ren/13318-en.html

[25] Korzynietz R, Brioso JA, del Río A, Quero M, Gallas M, Uhlig R, Ebert M, Buck R, Teraji D. Solugas - comprehensive analysis of the solar hybrid Brayton plant. Sol Energy 2016;135:578-89.

[26] Liu Q, Bai Z, Wang X, Lei J, Jin H. Investigation of thermodynamic performances for two solar-biomass hybrid combined cycle power generation systems. Energy Convers Manag 2016;122:252-62.

[27] Le Roux W, Bello-Ochende TMJ. A review on the thermodynamic optimisation and model of the solar thermal brayton cycle. Renew. Sust. Energy Rev 2013;28: 677-90.

[28] Osorio JD, Hovsapian R, Ordonez JC. Dynamic analysis of concentrated solar supercritical $\mathrm{CO}_{2}$-based power generation closed-loop cycle. Appl Therm Eng 2016; 93:920-34.
[29] McMahan A, Klein S, Reindl D. A finite-time thermodynamic framework for optimizing solar-thermal power plants. J Sol Energy Eng 2007;129:355-62.

[30] Zare V, Hasanzadeh M. Energy and exergy analysis of a closed Brayton cycle-based combined cycle for solar power tower plants. Energy Convers Manag 2016;128: 227-37.

[31] Barigozzi G, Perdichizzi A, Gritti C, Guaiatelli I. Techno-economic analysis of gas turbine inlet air cooling for combined cycle power plant for different climatic conditions. Appl Therm Eng 2015;82:57-67.

[32] Kalathakis C, Aretakis N, Roumeliotis I, Alexiou A, Mathioudakis K. Concentrated solar power components toolbox in an object oriented environment. Simul Model Pract Theory 2017;70:21-35.

[33] Santos MJ, Miguel-Barbero C, Merchan RP, Medina A, Calvo Hernandez A. Roads to improve the performance of hybrid thermosolar gas turbine power plants: working fluids and multi-stage configurations. Energy Convers Manag 2018;165: 578-92.

[34] Santos MJ, Merchan RP, Medina A, Calvo Hernandez A. Seasonal thermodynamic prediction of the performance of a hybrid solar gas-turbine power plant. Energy Convers Manag 2016;115:89-102.

[35] Heywood J. Internal combustion engine fundamentals. McGraw-Hill; 1988.

[36] Collado FJ. Preliminary design of surrounding heliostat fields. Renew Energy 2009; 34:1359-63.

[37] Collado FJ. Quick evaluation of the annual heliostat field efficiency. Sol Energy 2008;82:379-84.

[38] Zhang M, Yang L, Xu C, Du X. An efficient code to optimize the heliostat field and comparisons between the biomimetic spiral and stagerred layout. Renew Energy 2016;87:720-30.

[39] Spelling J. Hybrid solar gas-turbine power plants. Ph.D. thesis. Stockholm, Sweden: KTH Royal Institute of Technology, Department of Energy Technology; 2013.

[40] Falcone PK. A handbook for solar central receiver design. Sandia National Labs 1986;SAND 86-8009.

[41] Collado F, Guallar J. A review of optimized design layouts for solar power tower plants with campo code. Renew. Sust. Energy Rev 2013;20:142-54.

[42] Stine WB, Geyer M. Power from the sun. http://www.powerfromthesun.net/book. html; 2001.

[43] Leary PL, Hankins JD. A user's guide for MIRVAL- a computer code for comparing designs of heliostat-receiver optics for cental receiver solar power plants. Tech. Rep., Sandia Laboratories; 1979.

[44] Duffie J, Beckman W. Solar engineering of thermal processes. Hoboken, New Jersey: John Wiley and Sons; 2006.

[45] Merchan RP, Santos MJ, Medina A, Calvo Hernandez A. Thermodynamic model of a hybrid brayton thermosolar plant, Renew. Ener, vol. 128; 2018. p. 473-83. doi: doi://dx.doi.org/10.101016/j.renene.2017.05.081.

[46] Olumayegun O, Wang M, Kelsall G. Closed-cycle gas turbine for power generation: a state-of-the-art review. Fuel 2016;180:694-717.

[47] Coco-Enríquez L, Muñoz Anton J, Martínez-Val JM. New text comparison between $\mathrm{CO}_{2}$ and other supercritical working fluids (ethane, $\mathrm{Xe}, \mathrm{CH}_{4}$, and $\mathrm{N}_{2}$ ) in linefocusing solar power plants coupled to supercritical Brayton power cycles. Int $\mathrm{J}$ Hydrogen Energy 2017;42:17611-31.

[48] Lemmon EW, Huber ML, McLinden MO. NIST standard reference database 23: reference fluid thermodynamic and transport properties-REFPROP, version 9.1, national institute of standards and technology. Gaithersburg: Standard Reference Data Program; 2013.

[49] Meteosevilla. http://www.meteosevilla.com. http://www.meteosevilla.com.

[50] Relloso E, García E. Tower technology cost reduction approach after Gemasolar experience. Sol. Proc. 2015;69:1660-6.

[51] Peterseim JH, White S, Tadros A, Hellwig U. Concentrated solar power hybrid plants, which technologies are best suited for hybridisation? Renew Energy 2013; 57:520-32.

[52] [link], https://www.thermoflow.com.

[53] [link], https://www.solarturbines.com. 